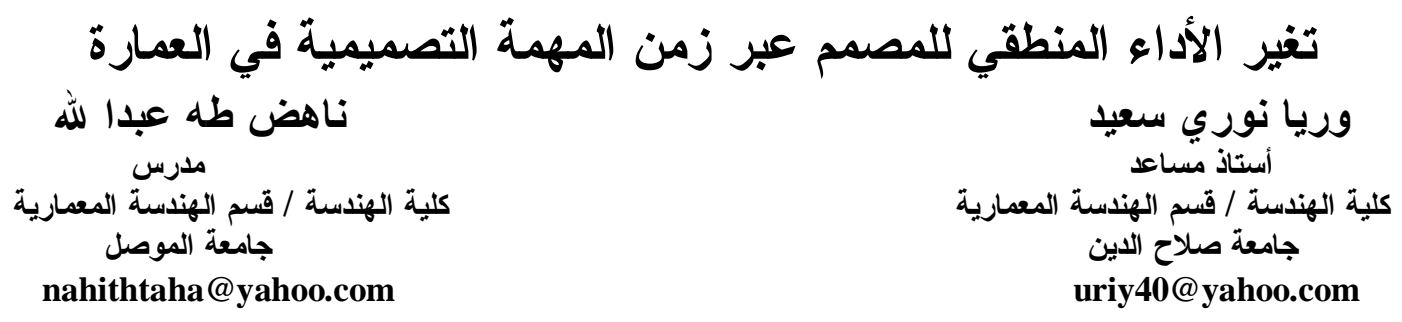

\title{
الخلاصة
}

رغم أن العديد من الدراسات قد حاولت، تقليص الفرق بين النماذج المفاهيمية التي تعرضت لحفئ لحصر العمليات

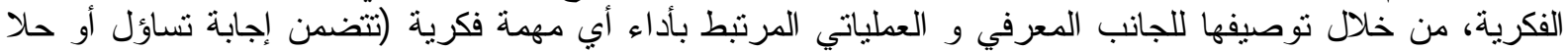

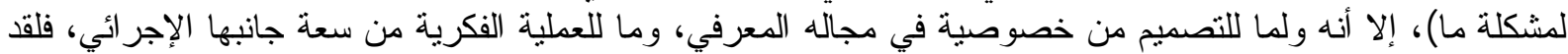

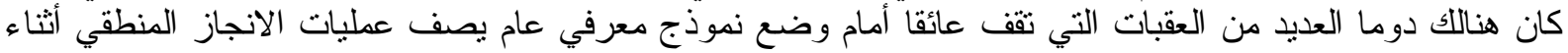

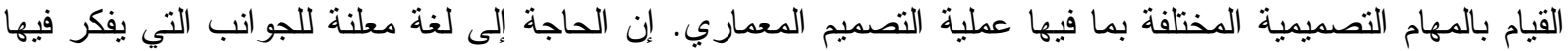

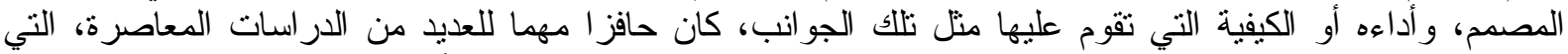

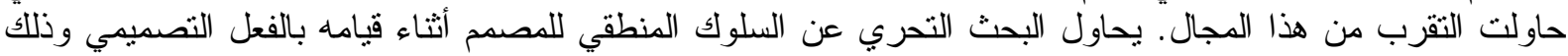

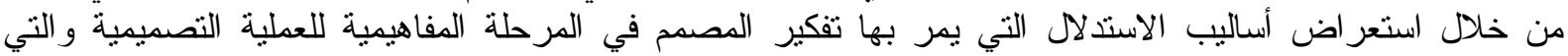

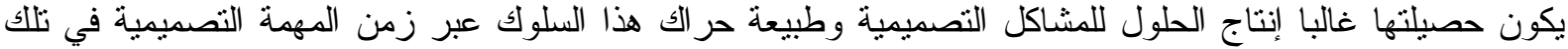

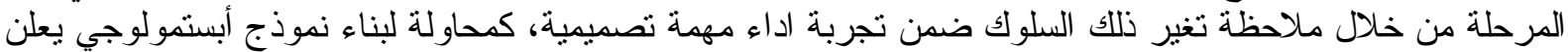

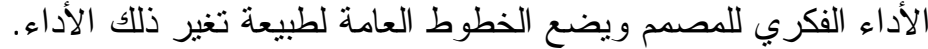
كلمات مفتاحيه: المنطق، البنية المنطقية، الاستدلال المعماري، التصميم المعماري الأدياء

\section{The alteration of designer logical performance during architectural design task}

\author{
Nahith Taha Abdulla \\ Lecturer \\ University of Mosul \\ College of Engineering L/Dept. of Architecture
}

\author{
Uriya Noory Saeed \\ Assistant Professor \\ University of Salahaldeen \\ College of Engineering L/Dept. of Architecture
}

\begin{abstract}
Although many studies have tried to reduce differences between conceptual models of thinking processes, through the description of the operational performance of any intellectual task includes problem solving, however, because of the design specificity in this regard, and diversity of its motion, there were always, many of obstacles that stand in the way of developing a model describes the operations of reasoning achievement during different architectural design phases. The need for explicit language of designer thinking, and architects performance or how they underlined such aspects, was incentive concern for many contemporary studies, which tried to cover this area in one way or another. This research tries to investigated designer logical behavior during a design process, through the review of inference acts, during conceptual stage of that process, also it tries to investigate the nature of the mobility of this behavior across time of the task.
\end{abstract}

Keywords: Logic, Logical Structure, Architectural Inference, Architectural Design 


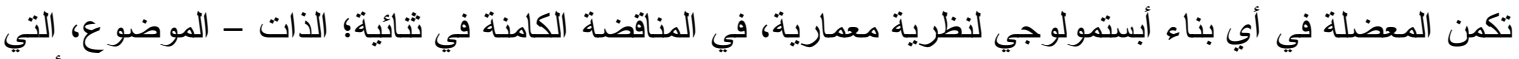

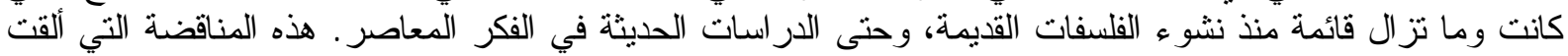

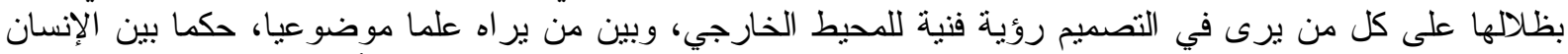

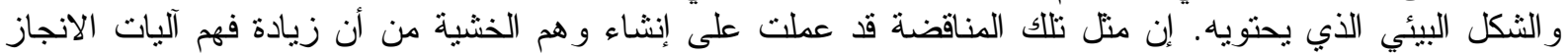

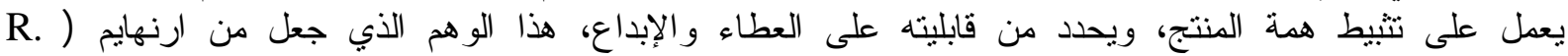

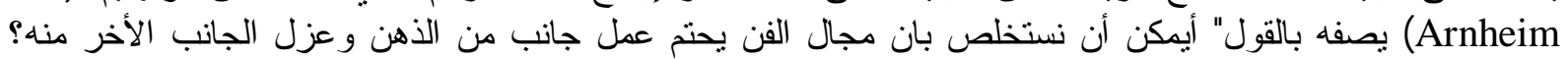

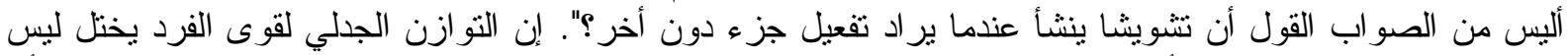

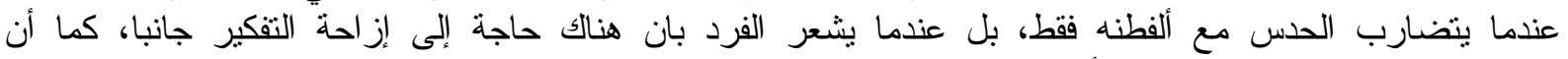

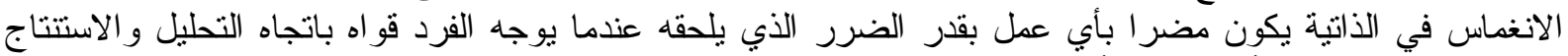

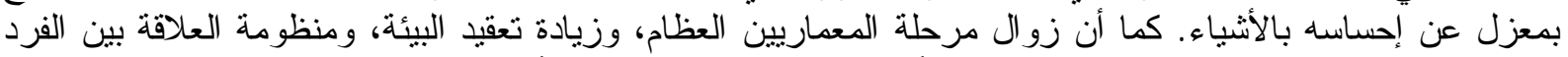

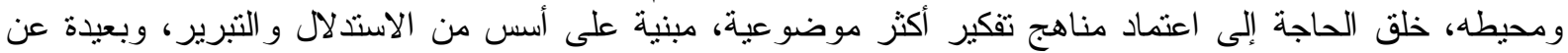

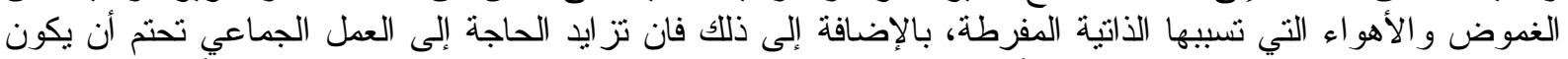

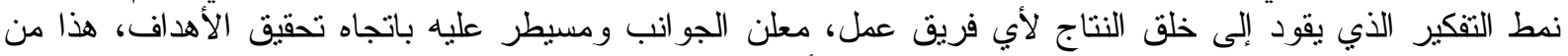

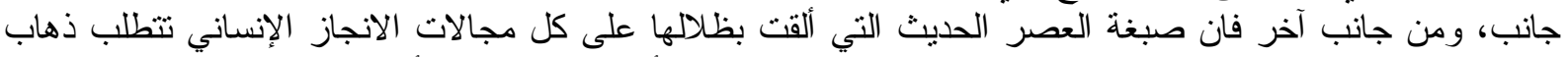

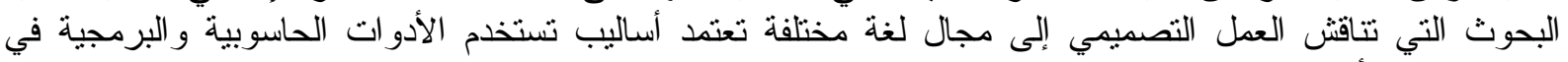
توصيف هذاً الأداء.

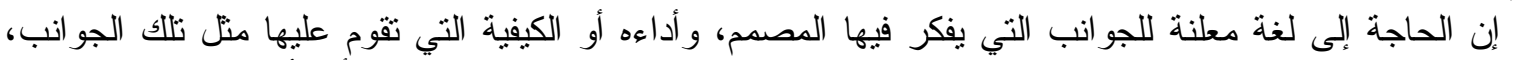

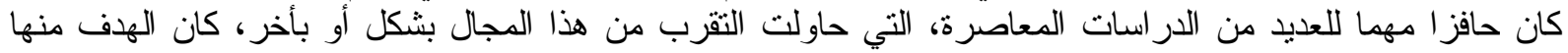
بناء جهاز معرفي، يساعد على الكثف عن العات العمليات ألفكرية المرتبطة بالعملية التصميمية.

المشكلة البحثية

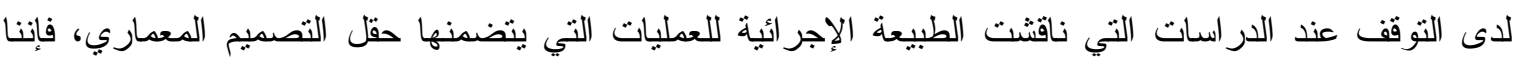

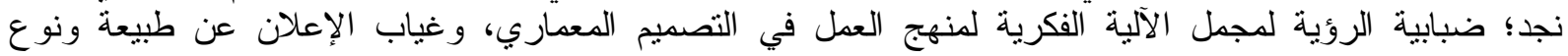

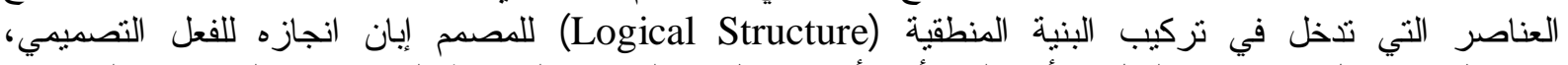

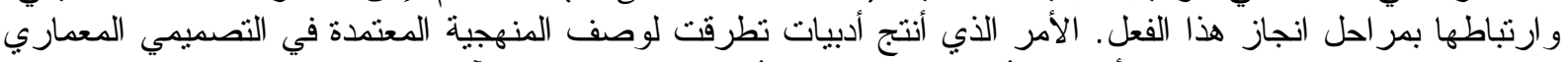

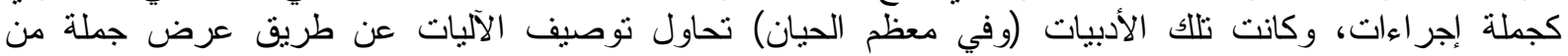

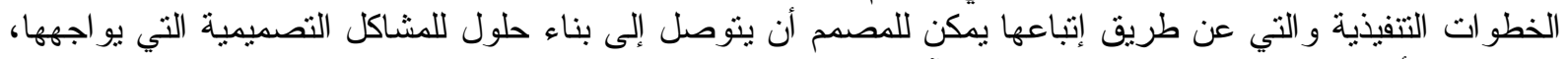

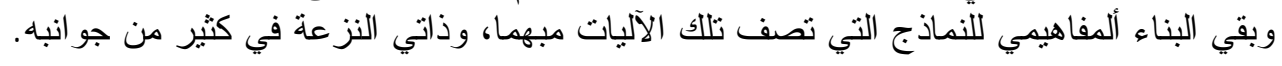

\section{هدف البحث}

يهدف البحث إلى مر اقبة البنية المنطقية التي يكون عليها السلوك التصميمي (Design Behavior) أثناء أداء

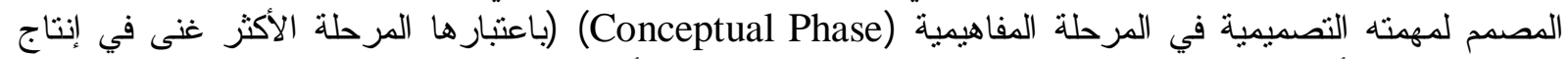

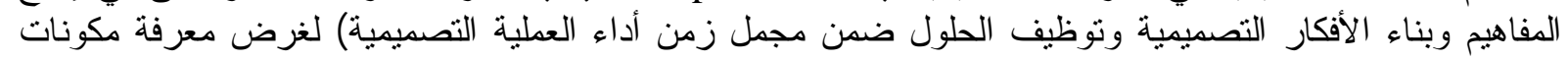

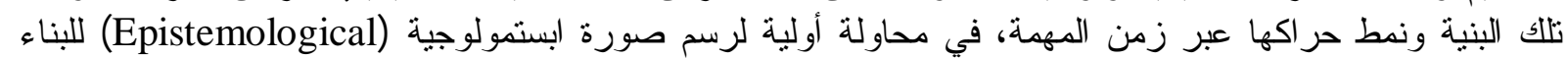

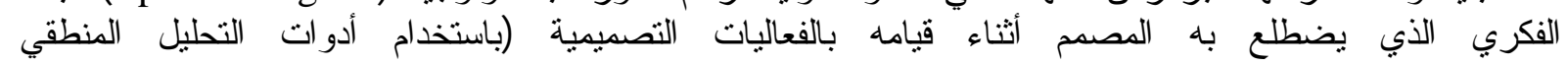
ألاسترجاعي(Retrospective) لمهمة تصميمية محددة كلف بها عدد من المبحوثين كمنهج لتحقيق هذا الهدف).

مناهج التصميم المعماري

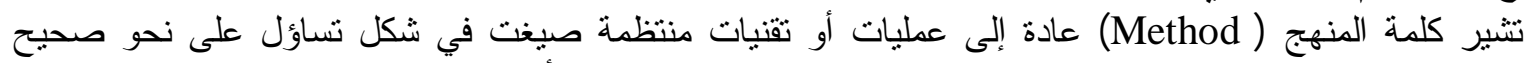

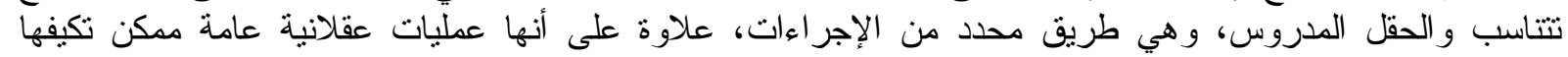

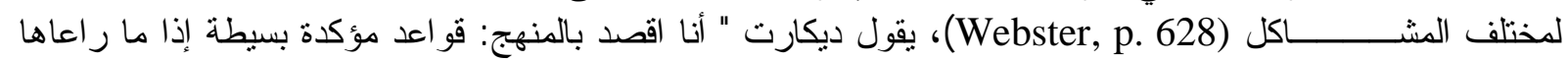

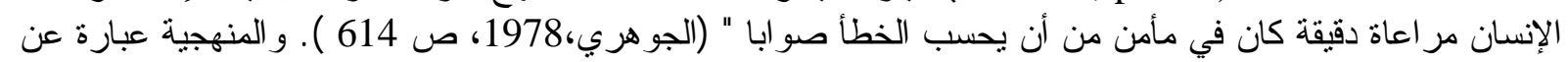

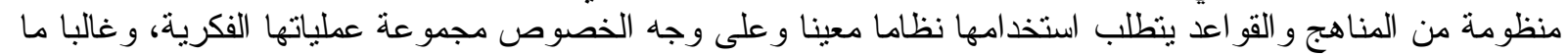
ترد في سياقات يجعلها تشير إلى مصطلح أوسع من المنهج أو انه يضم عددا من المناهج (Gregory, 1966, p19).

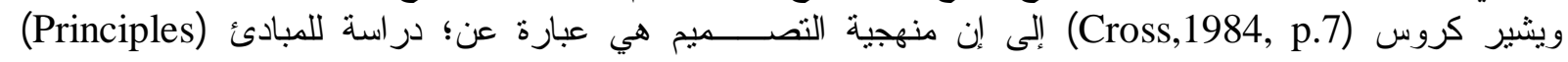

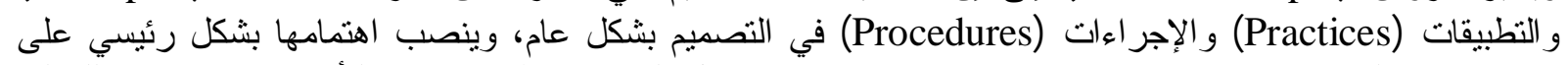
كيفية تحقيق التصميم بغايته، و وكذا فهي تتضمن در اسة كيفية عمل المصمم وطرق تفكيره لتأسيس بنية ملأنئمة للتعملية 
التصميمية ولتطوير ونطبيق طرق تصميمية جديدة، وهذا بدوره ينعكس إيجابا على المعرفة التصميمية ونطبيقاتِها

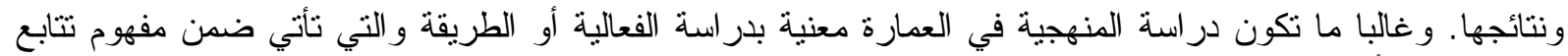

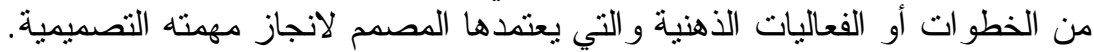

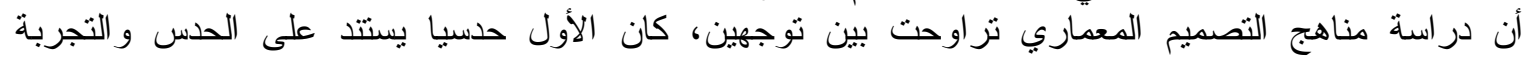

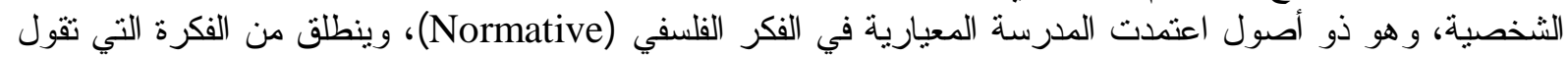

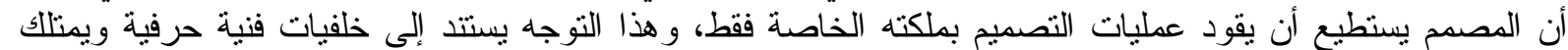

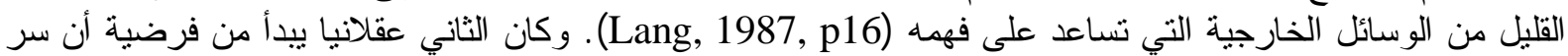

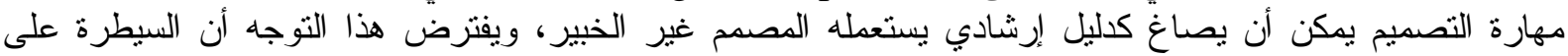

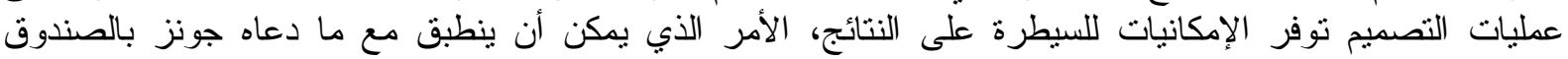

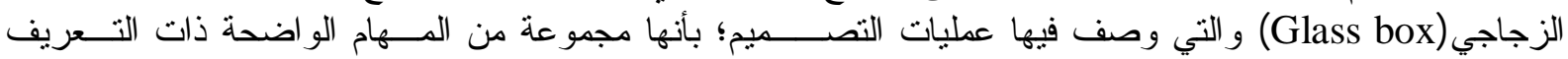

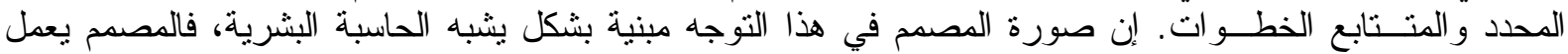

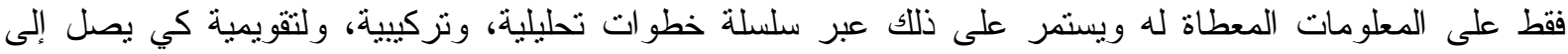

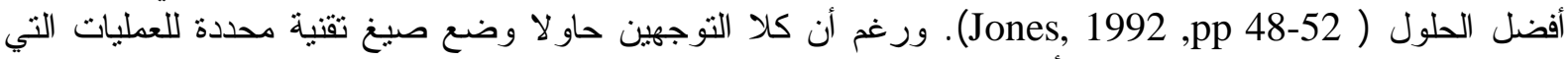

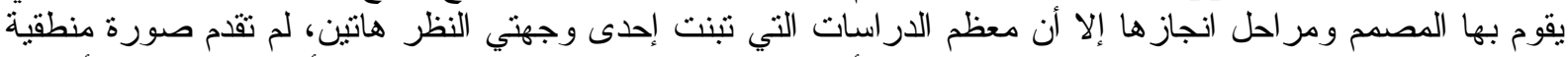

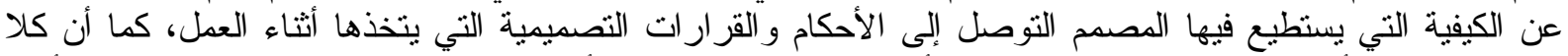

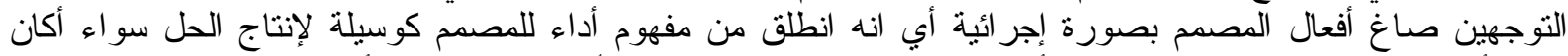

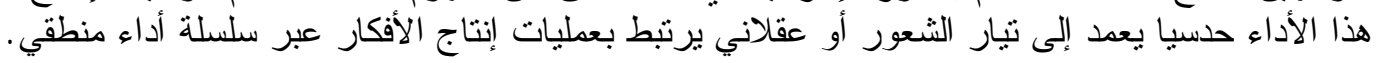

\section{العمليات الفكرية في التصميم}

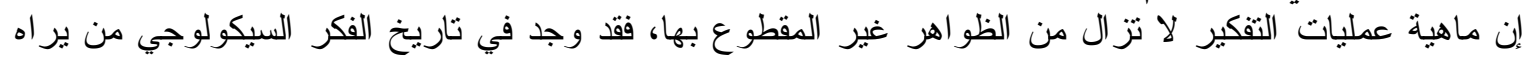

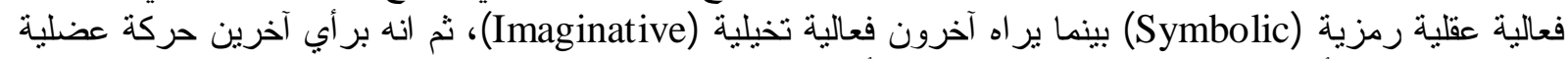

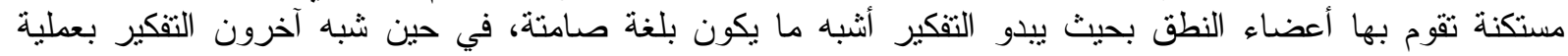
الاختز ال (Reduction) للمعلومات المستقاة من الخارج. غير أن لعلم النفس المعرفي (Cognitive Psychology)

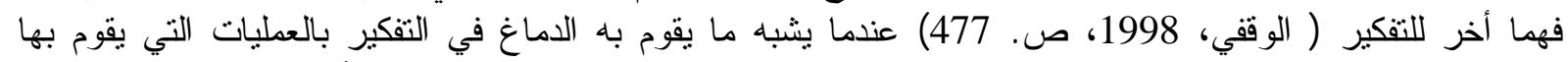

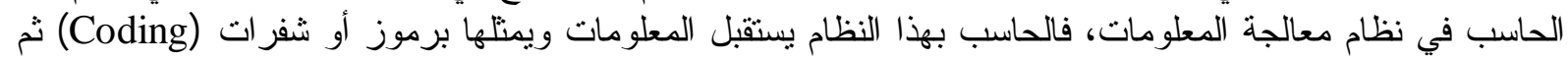

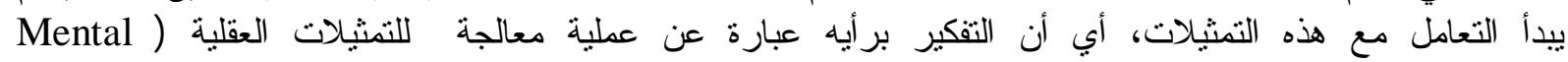
.(Representations ويشير بياجيه (Jean Piaget) بهذا الصدد إلى أن عملية التفكير في مجملها هي عملية تكييف (Adaptation) بين

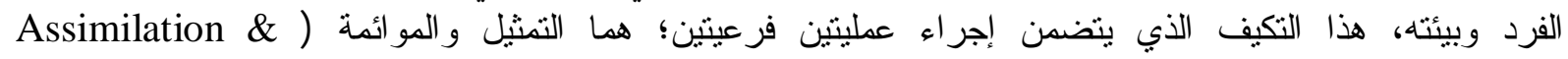
(Accommodation

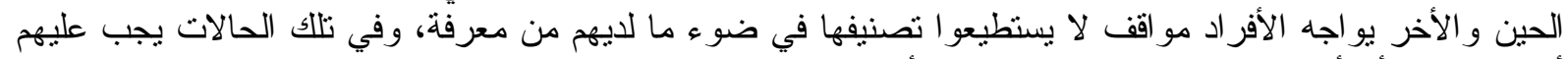

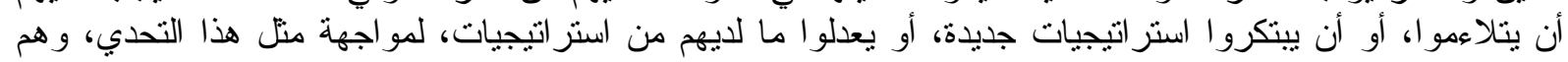

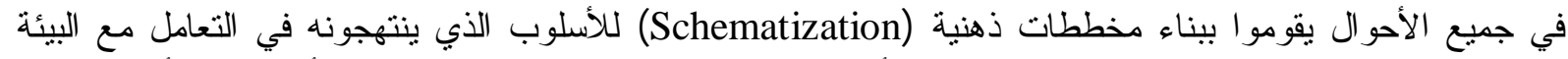

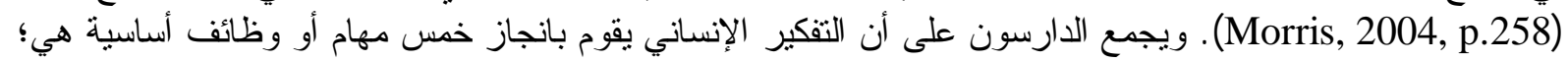

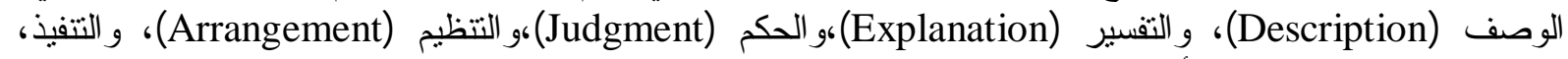
وتظهر هذه الوظائف كما لو أنها تكون دائرة فكرية.

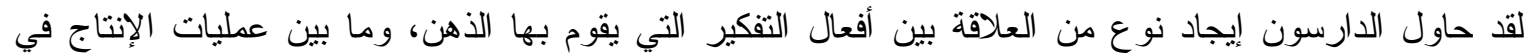

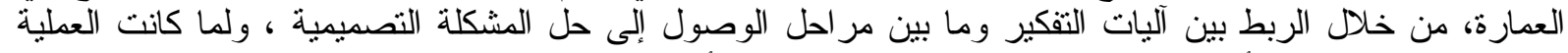

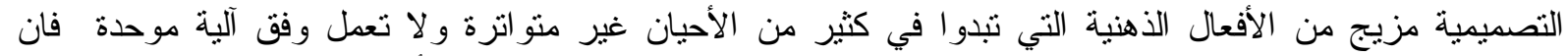

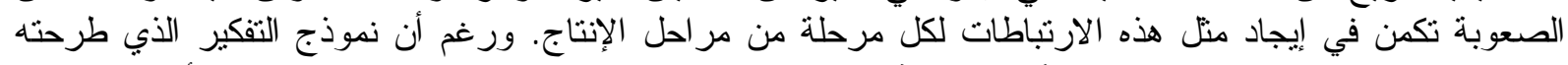

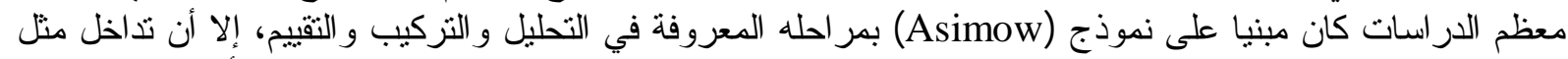

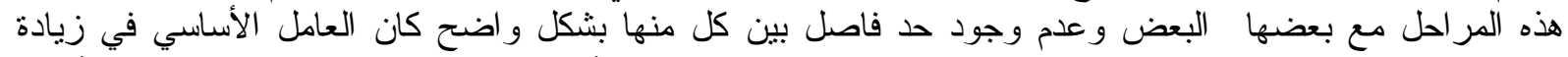

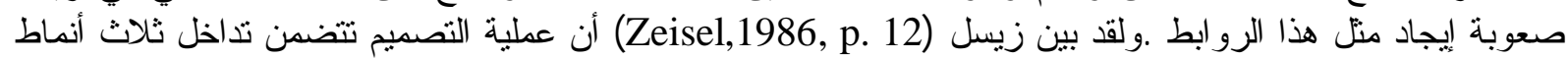

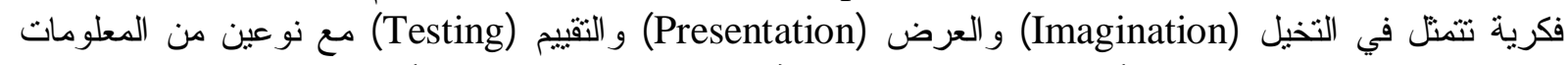

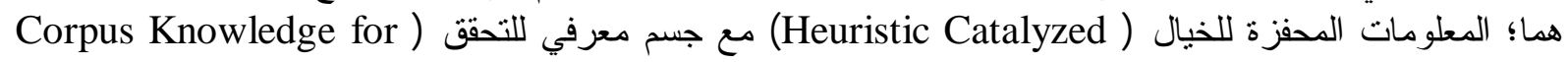
الإعيدة) يسير بشكل لولبي (Checking) بتقدم الفعل التصميمية ويتم عن طريق سلسلة من نطابق المفاهيم بالانتقالات

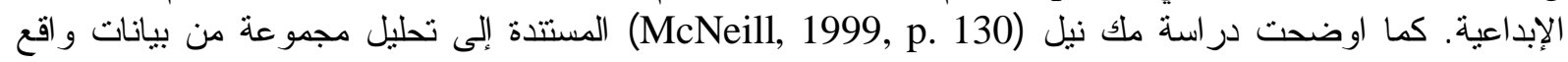


الحال التطبيقية أن متل هذه التداخلات أثناء العمل التصميمي، تحدث لنتكيل ما طلق عليه اسم فعاليات الثقييم التحليلي

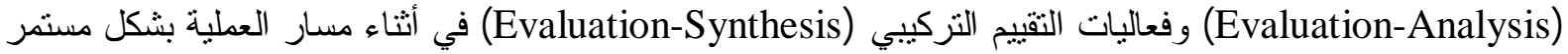

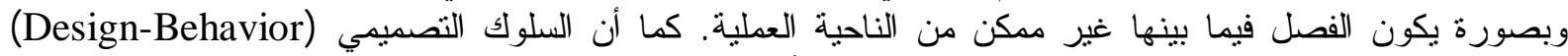

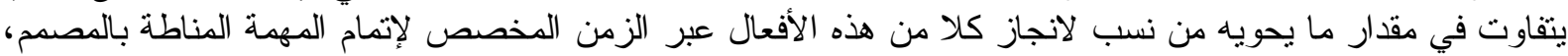

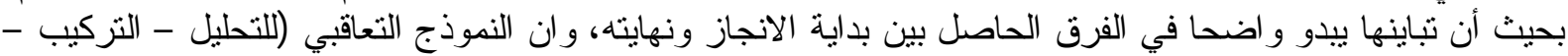

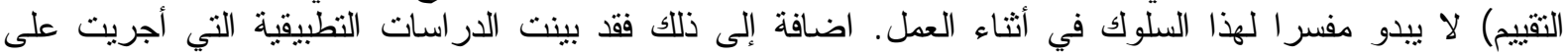
مجاميع من طلاب العمارة في أثناء عملهم (Leclercq, 2002, p. 2)، أن انساق الأفعال الفكرية غالبا ما تنتباين في

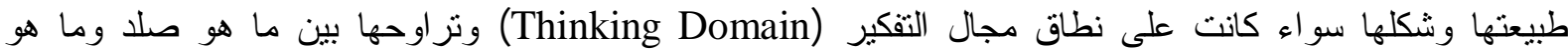

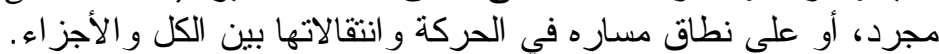

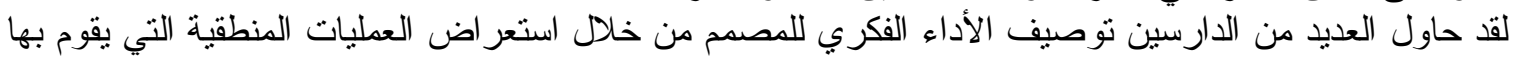

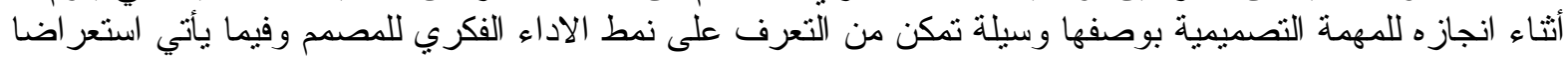

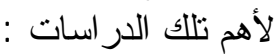

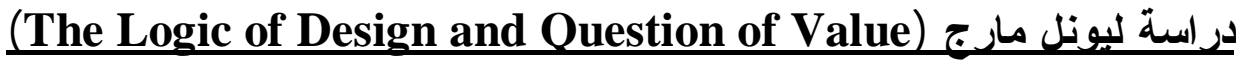

حاول مارج (L. March) في در استه المنشورة عام (1976) بناء طروحاته حول الهيكلة الفكرية لعملية التصميم

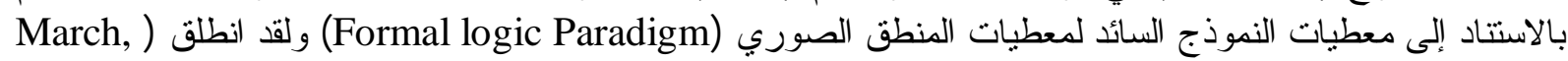

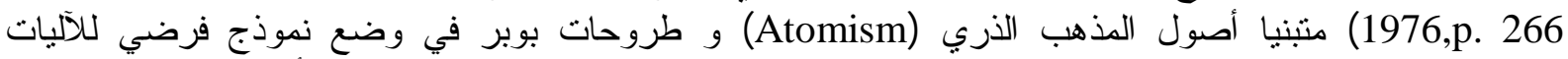

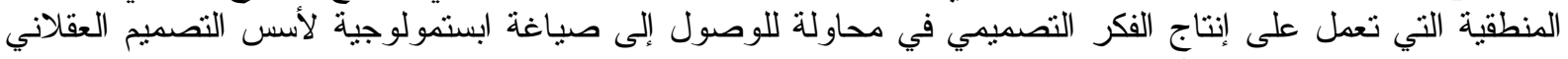

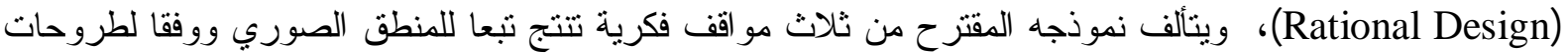

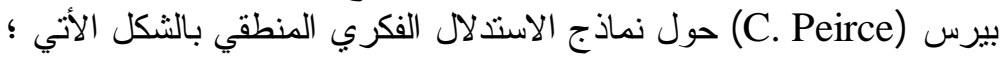

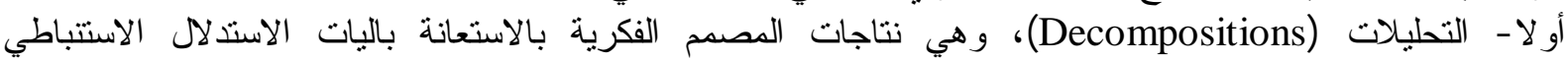

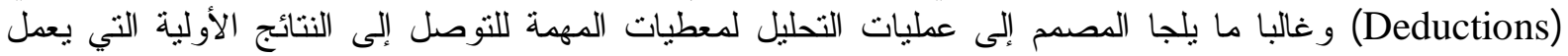

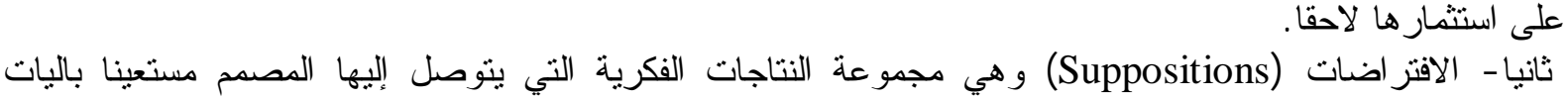

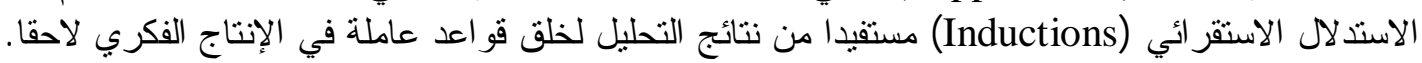

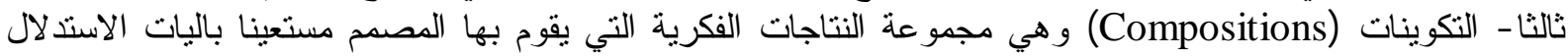

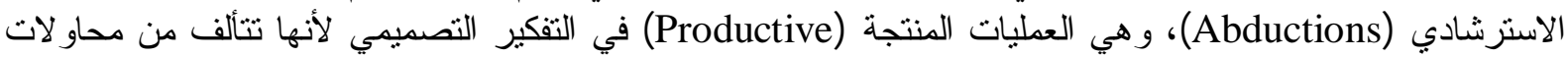

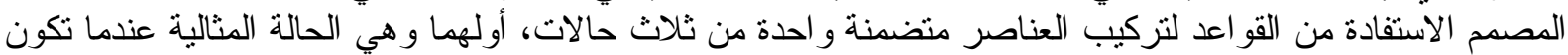

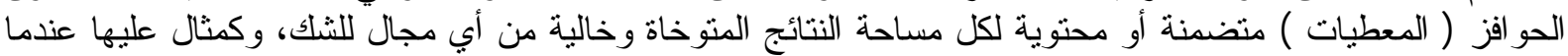

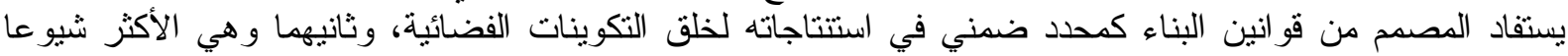

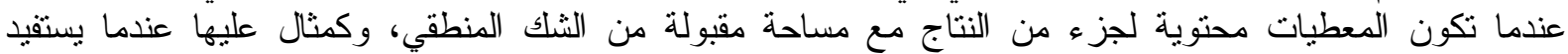

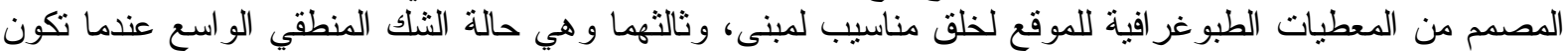
المعطيات خارجة عن مساحة تغطية النواتج، وتظهر هذه الحالة في تضمين المهية التصميمية عناصر دلالية ومعنوية التئية

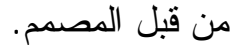
لقد طرح مارج قيام المصمم بإجر اءء عمليات الاستتناج الأساسية ضمن حركته الفكرية، ورغم أن الاستدلال

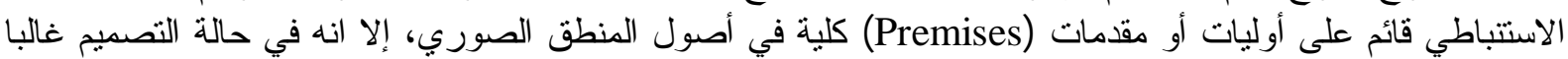

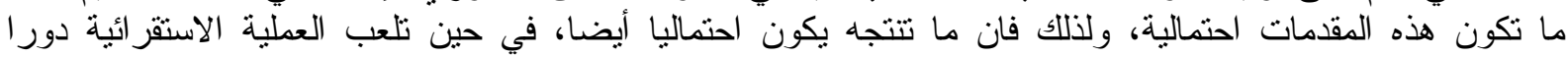

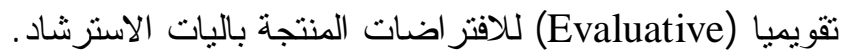

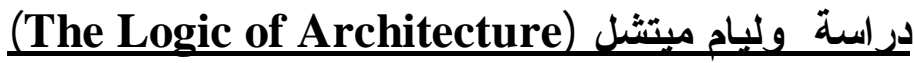

حاول ميتشل (W. Mitchell) في كتابه المنشور عام (1990) بناء لغة مفردات (Vocabularies) أطلق عليها

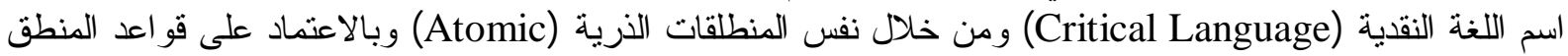

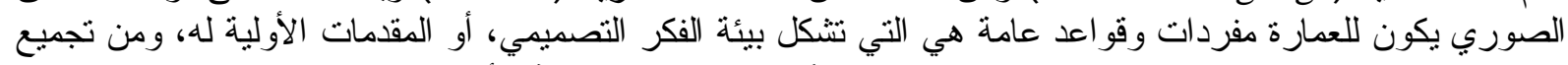

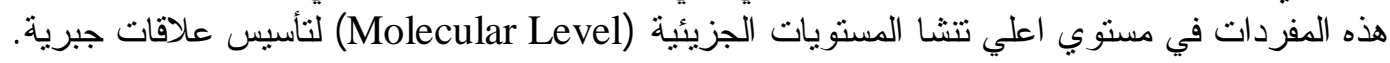
لقد انطلق ميتشل (Metchill,1990, p.70) من العلاقة بين الثكل و الوظيفة لتقرير إمكانية المصدم الفكرية في توظيف المعرفة المشتقة من الثكل لملائمة الوظيفة المراد تحقيقها بعد تحويل مفردات الثكل إلى ملى محمولات منات منطقية

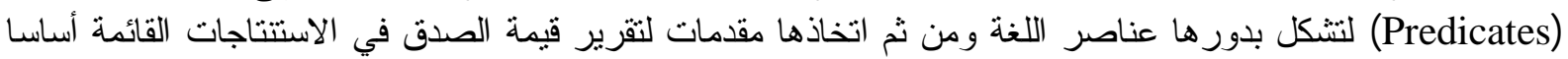


على الاستتباطات المنطقية. ويفرق ميتشل في الأداء الفكري للمصمم ما بين استخدامه للقو اعد و الحقائق و البديهيات التي

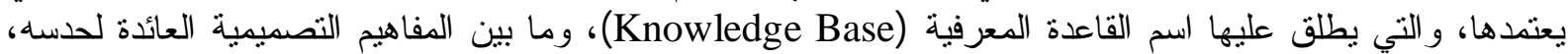

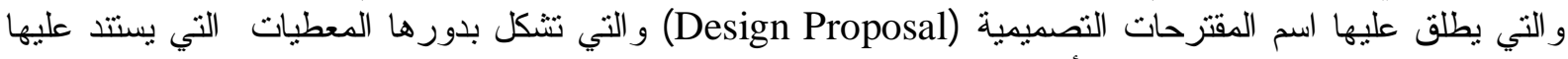

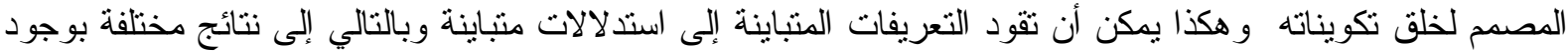
القاعدة المعرفية المنقق عليها، كما أنها تؤدي بالضرورة إلى إلى أغناء قو اعد التحويل التي يستثمرها التهاتية المصمم للإنتاج.

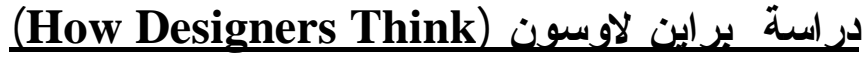

ينطلق لاوسون (B. Lawson)، في كتابه المنشور عام (1997) من أسس المدرسة الإدر اكية في علم النفس

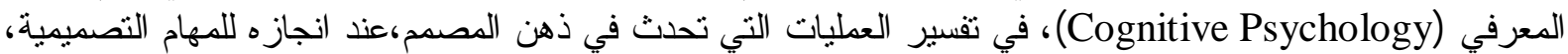

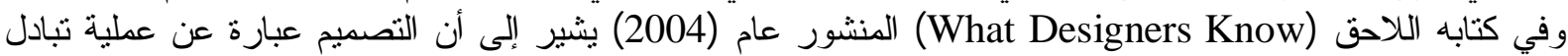

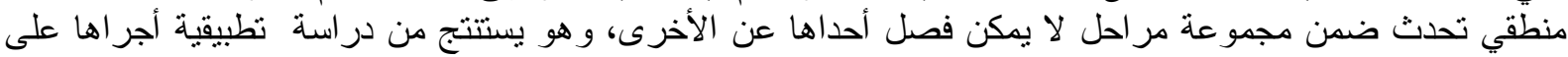
مجموعة من المبحوثين، إلى أن العملية التصميمية هي عبارة عن عملية تفاوض (Negotiation) بين المشكلة و الحل

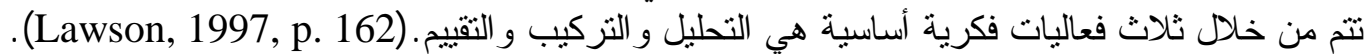

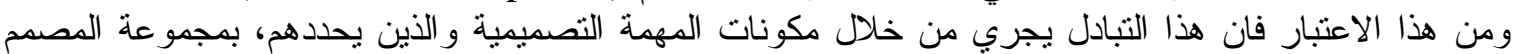

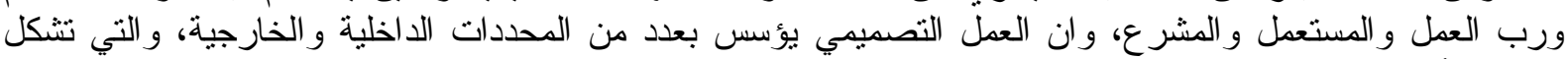

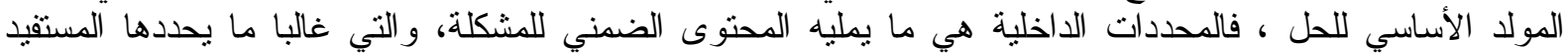

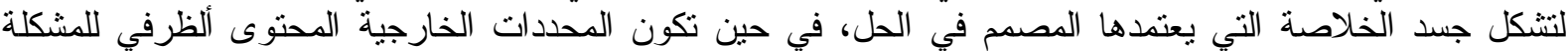
و التي تغطي المؤثر ات العامة للحل، كما أنها تزود بالإمكانيات المكانية و الزمنية لمجال تأثثر المشكلة ولذلك فهي تكون

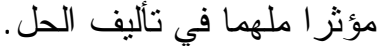

إن الرؤية المعمقة لتلك الدر اسات تفيد بوضوح انه حتى تلكل الدر اسات التي ناقتشت الفعل الفكري التصميمي لم تقدم

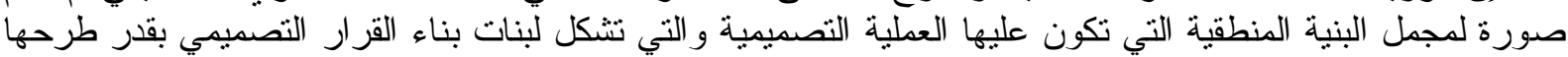

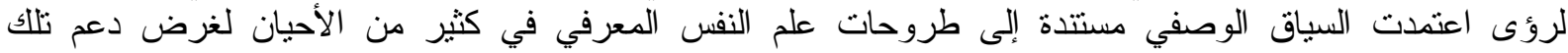

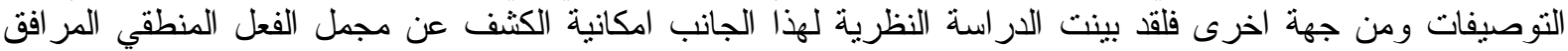
اللعملية التصميمية من خلال المؤشر ات التات التالية: -

1 - اعتماد منهج نطبيقي انطلاقا من ما يسمى في لني علم النفس المعرفي باسم تحليل المسودات ( Protocol (Analysis

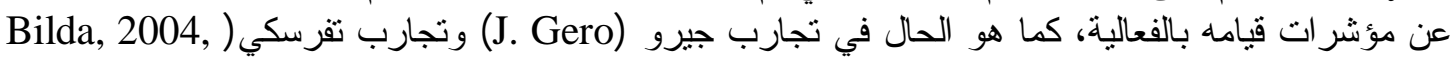
. (pp.12-142

2 - الاستتاد إلى ما بطرحه المصمم من وصف لمجريات العملية باعتبار ها دالة القيام بالفعالية التصميمية و الكثف

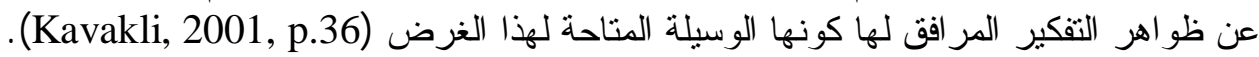

3 - ربط أداء المصمم مع المحتوى الوصفي المقدم من قبله لعملية التصميم التي أنجز ها (Suwa, 1997,p.10).

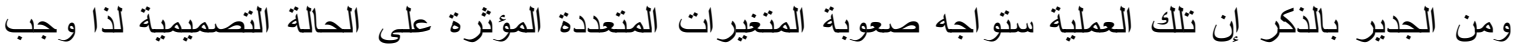

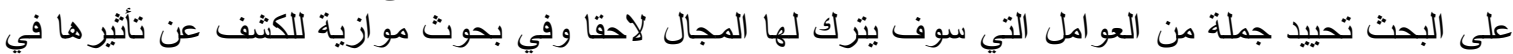

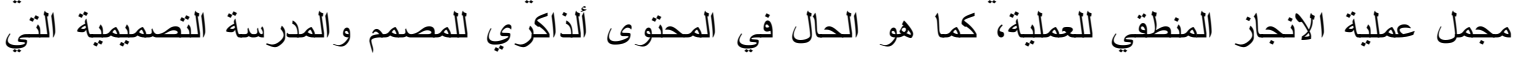

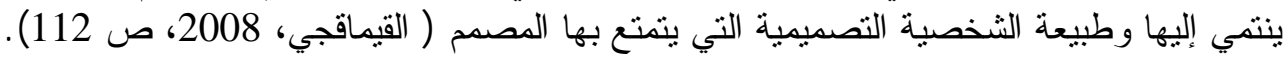

\section{التجربة البحثية}

لغرض الوقوف على طبيعة الأداء الفكري للمصمم وجب تصميم تجربة بحثية (انظر ملحق رقم 1) كلفت بها عينة

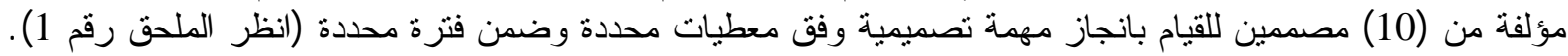

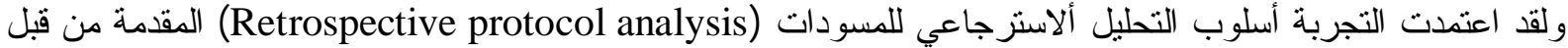

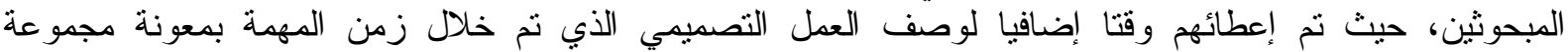

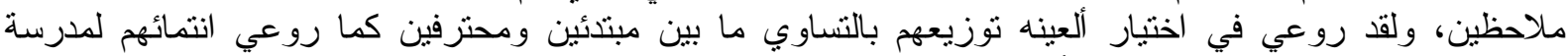

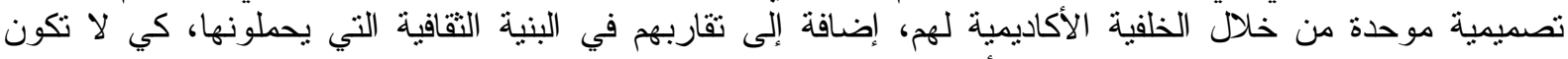

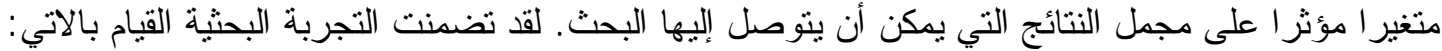

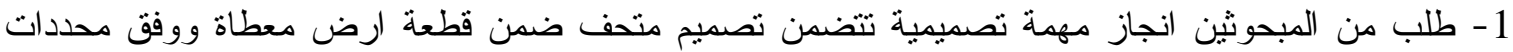

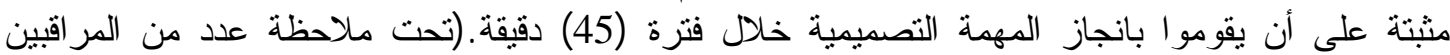

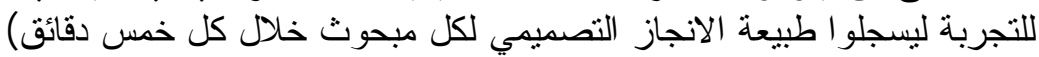


2 - بعد انجاز المهام التصميمية طلب من كل مبحوث (بعد أن عرضت عليه انجاز اته) وصف العملية الفكرية التي قام بها للتوصل إلى ما توصل إليه من حلول وضمن وقت مفتوح وتدوين ذللك كتابيا بمقالة تصميمية وبمساعدة الملاحظ.

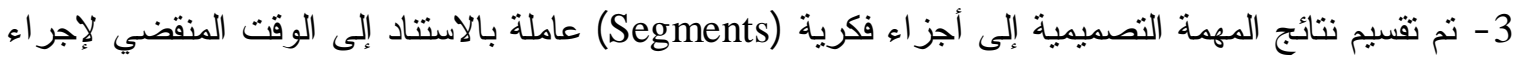

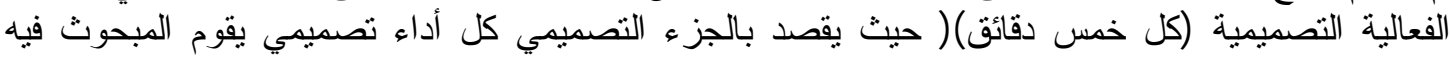

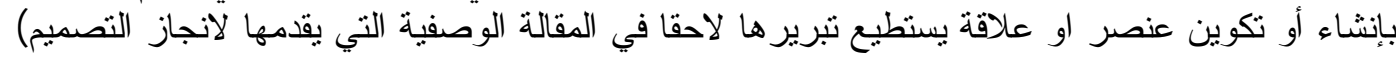

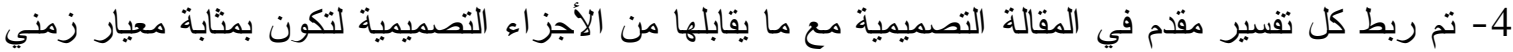

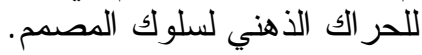

5 - ونم فحص المقالة التصميمية التي قدمها المفحوصين بالكشف عن ما تتضمنه من أفعال منطقية خلال زمن

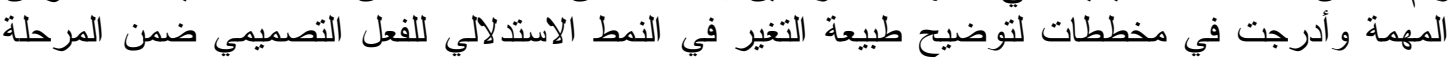
المفاهيمية.

الآليات المنطقية الفاعلة في العملية التصميمية

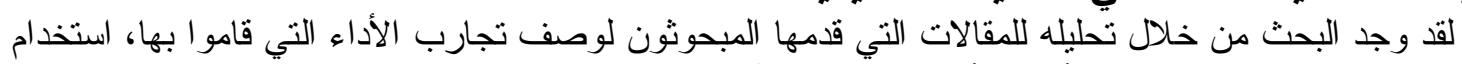

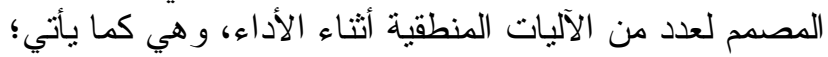

1 - الاستخ لال القضوي (Proposition Inference) و هو فعل قيمي (Immanency)، يستند فيه المصدم إلى اعتبار اته الذاتية ومخيلته، دون وجود مقدمات محددة له، واله

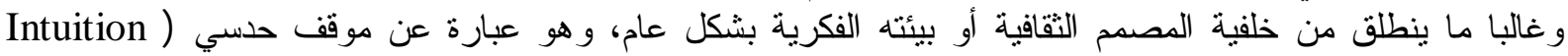
(Proposition

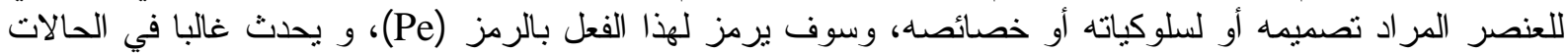
التي تكون فيها المعرفة المتوفرة حول العنصر غير واضحة وغير محددة ، وكما في المثال التالي الذي ورد في في مقالة

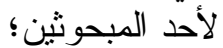

يمكن أن يكون المبنى بشكل هرم رباعي صريح، دون أي إضافة و الذي يعطي معنى الهيمنة والصلادة و القوة على المبنى ان ليك

2 - الاستدلال الاستتباطي (Deduction Inference)

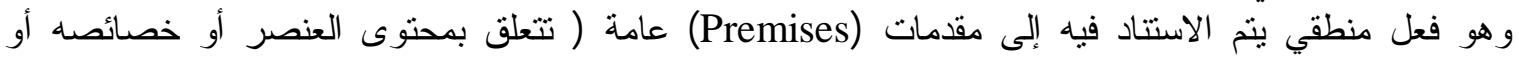

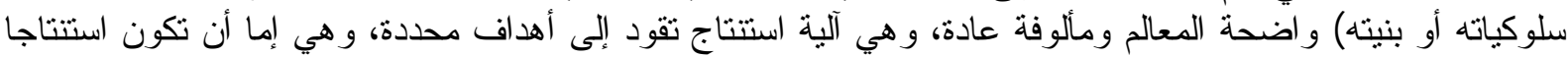
عاما وعند ذاك تكون استدلالا استتباطيا عاما وسوف يرمز لها بالرمز (De)، وكما في المثال الأتي الذي ورد في مقالة

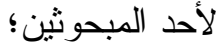

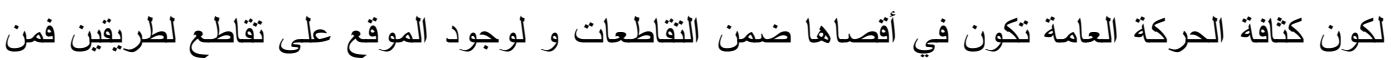
المفيد توقيع المدخل الرئيسي على محور التقاطئ فئع لاستقطاب اكبر زخم من الحركة النافذة.

أو أن الاستدلال بنطلق من آلية الممانلة (Analogy)، والتي تقود المصمم إلى خلق قياس للعنصر أو لسلوكه

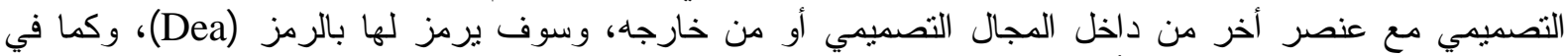
المثال التالي الذي ورد في مقالة لأحد المبحوثين؛

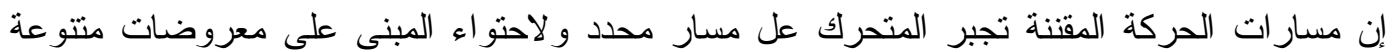

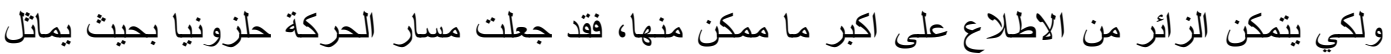

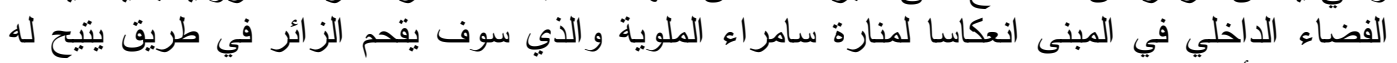

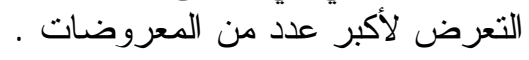

3 - الاستخ لال الاستقر ائي (Induction Inference)

و هو فعل منطقي يتم الاستتاد فيه إلى مقدمات ( تتعلق بمحتوى العنصر أو خصائصه أو سلوكياته أو بنيته) محددة

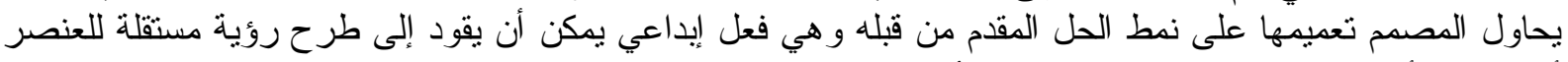

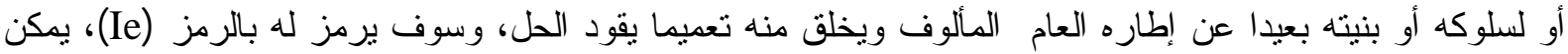


أن يأتي هذا التعميم منطلقا من حالة جزئية خاصة تعيد إنتاج الحل التصميمي في إطار رؤية شمولية أكثر اتساعا من مجرد معطيات العناصر الداخلة في التكوين، وكما في المثال التالي الذي ورد في مقالة لأحد المبحوثين؛

للمشروع قيمة حضارية تتبع من العلاقة التفاعلية بين معروضاته وز ائريه لذلك رأيت أن يتم تحفيز الزائر التهاء

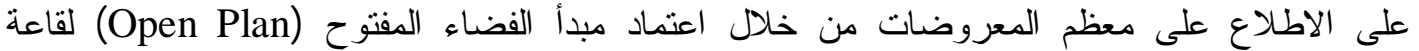

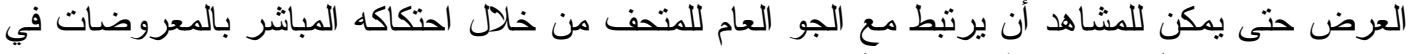

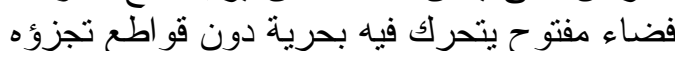

4 - الاستدلال الاسترشادي (Abduction Inference)

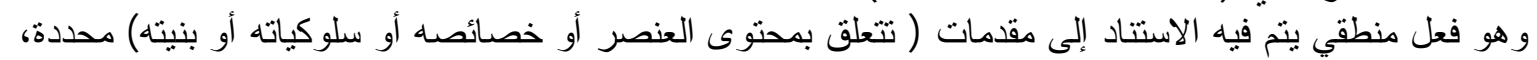

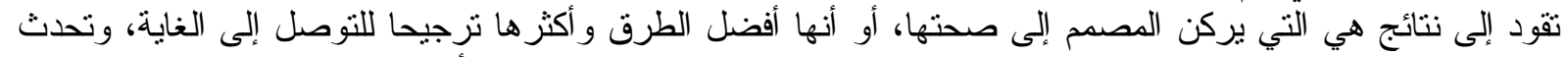

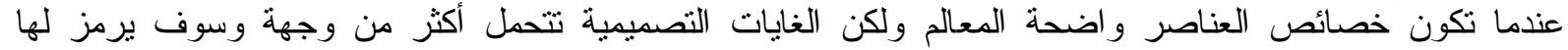
بالرمز (Ae)، وكما في المثال التالي الذي ورد في مقالة لأحد المبحوثين؛

لأن قاعة المعروضات هي السبب الأساسي في قدوم الزائرين لذا يكون من الأفضل وضعها في منطقة مركزية من المبنى.

ومن المفيد الإشارة هنا إلى أن أي من النتائج المستحصلة بالأفعال أنفة الذكر يمكن أن تكون قابلة للتعديل

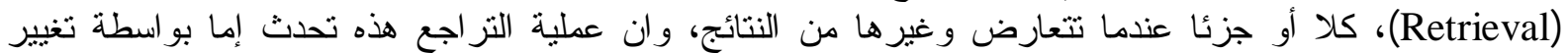
المقدمات التي انطلق منها المصمم لبناء نتاجه أو عن طرئ هاريق تغير الفعل ألاستتاجي المعتمد من قبله .

التحليل المنطقي للمقالة التصميمية (Logical Analysis of Design Discourse)

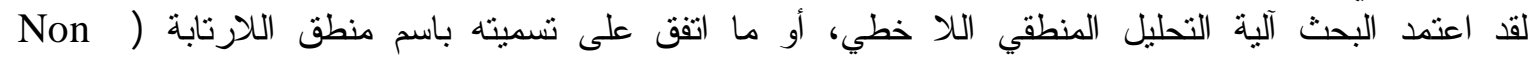

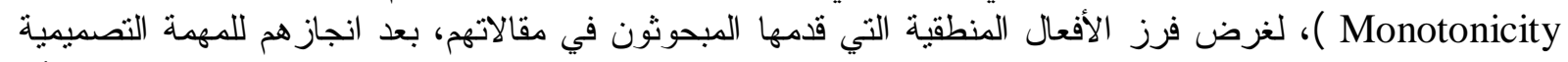

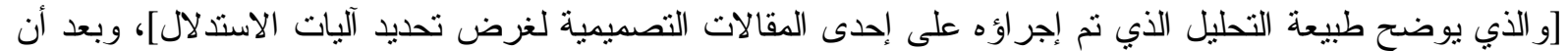

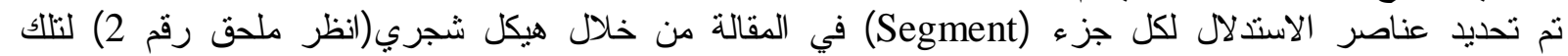

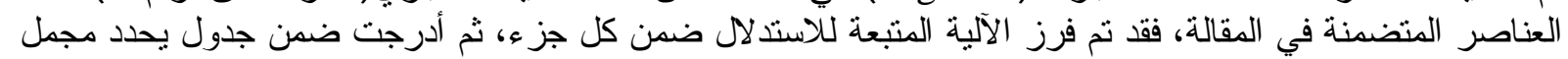

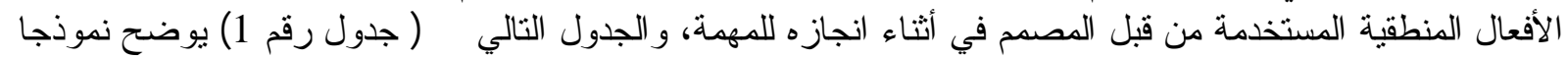
لما تقدم حيث يشير الى تكر ار الفعل المنطقي خلال كل فترة (59 دقائق من زمن المهمة التصميمية البالغة (45) دقيقة.

جدول رقم (1) يوضح إحدى نتائج تحليل تجارب الاداء التصميمي وطبيعة تو اجد الفعل المنطقي عبر زمن التجربة

\begin{tabular}{|c|c|c|c|c|c|c|c|c|c|c|}
\hline المجموع & 45 & 40 & 35 & 30 & 25 & 20 & 15 & 10 & 5 & الفعل/الزمن \\
\hline 6 & 0 & 0 & 1 & 0 & 0 & 4 & 1 & 0 & 0 & $\mathbf{P e}$ \\
\hline 5 & $\overline{0}$ & 1 & $\overline{0}$ & $\overline{0}$ & 2 & 1 & $\overline{0}$ & $\overline{0}$ & 1 & De \\
\hline 0 & 0 & $\mathbf{0}$ & $\overline{0}$ & 0 & 0 & 0 & 0 & 0 & 0 & Dea \\
\hline 2 & 0 & 0 & 0 & 1 & 1 & 0 & 0 & 0 & 0 & Ie \\
\hline 16 & $\overline{\mathbf{0}}$ & $\overline{\mathbf{0}}$ & 2 & 2 & 1 & 3 & 3 & 4 & 1 & $\overline{\mathrm{Ae}}$ \\
\hline 29 & 0 & 1 & 3 & 3 & 4 & 8 & 4 & 4 & 2 & المجموع \\
\hline
\end{tabular}

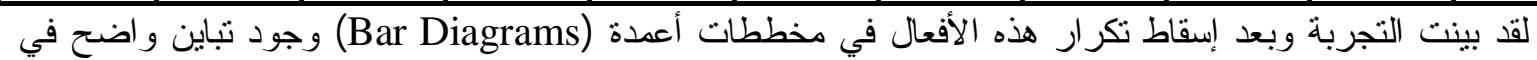

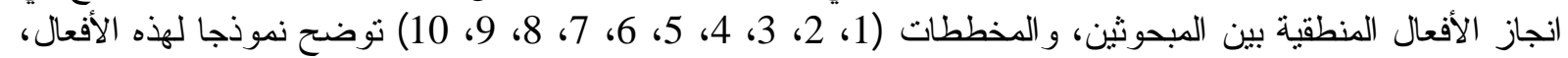
وتغير ها عبر زمن النجاز المهمة. النتائج و المناقشية أوضحت الإجر اءات التحليلية للأفعال المنطقية، و التي أنجزت على المطروح الكتابي للمهمة التصميمية، جملة من

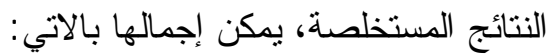




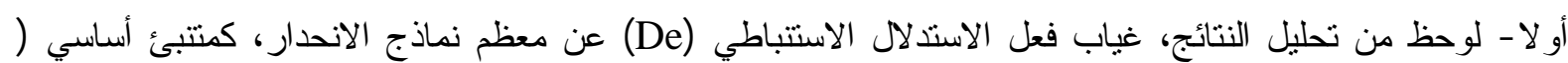
Predictor

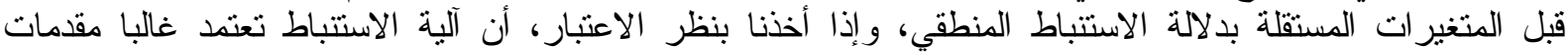

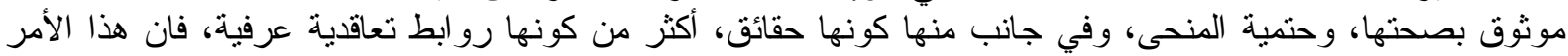

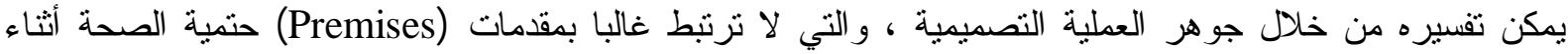

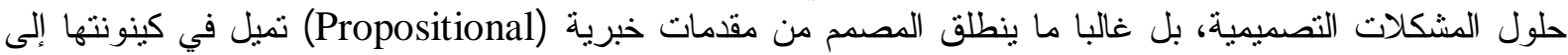

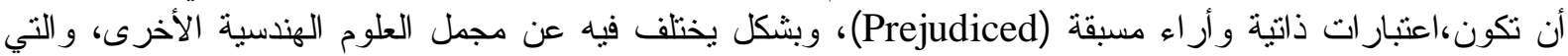

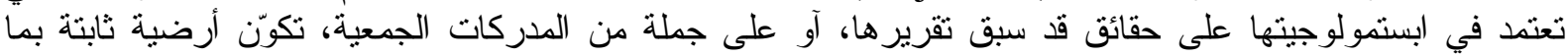

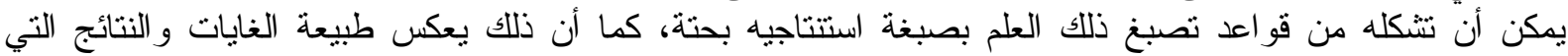

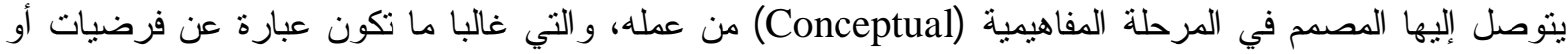
افتر اضات (Suppositions ) قابلة للاختبار ، أكثر من كونها حقائق ثنابتة.

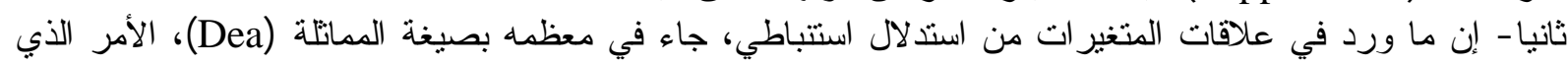

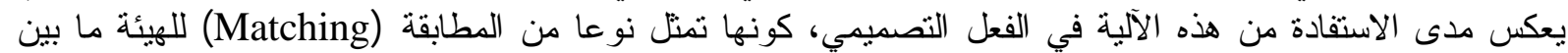

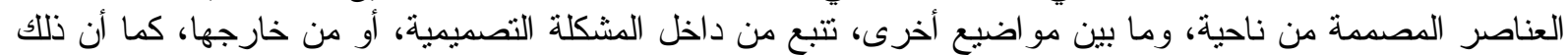

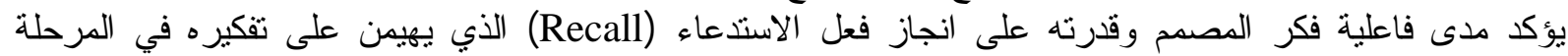

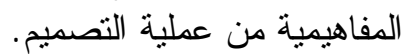
ثالثا - إن تكرار فعل الاستكلال القضوي (Pe) في أداء الصصمم، يعكس طبيعة الصورة الفكرية لما تتخذه المهمة

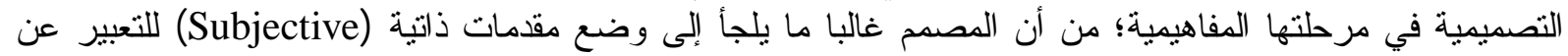

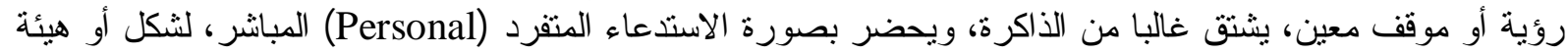

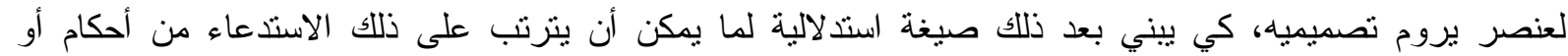

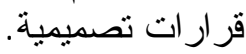

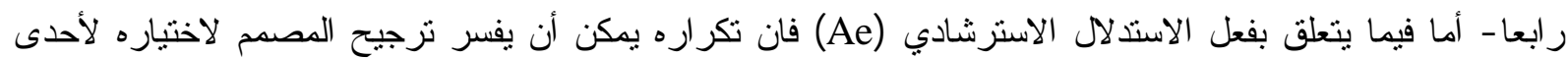

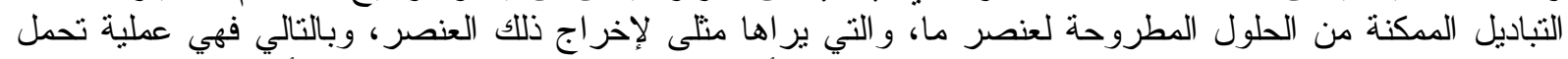

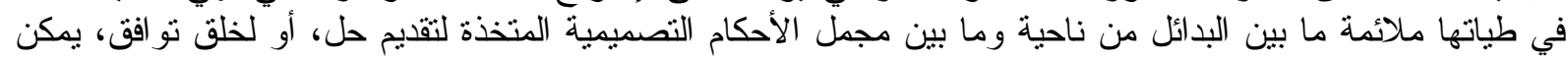

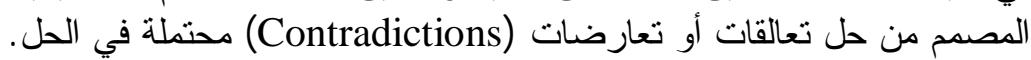

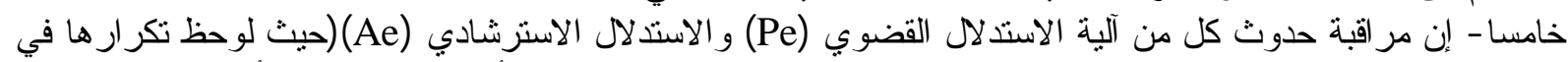

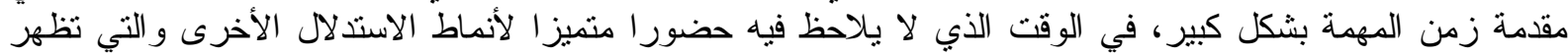

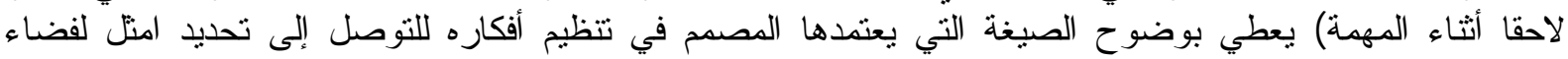

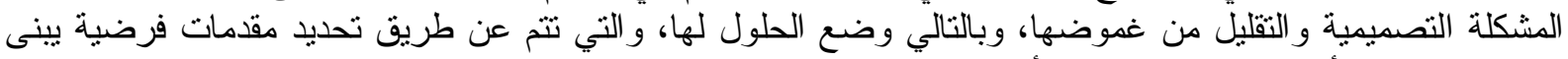

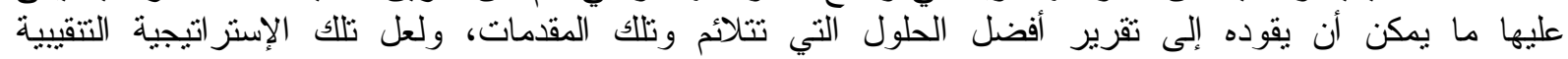
Goal (Heuristic) (Oriented)، أو موجهة نحو الهشكلة ذاتها (Problem Oriented).

استنتاجات البحث وتوصياته

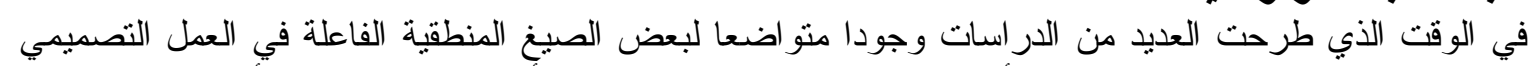

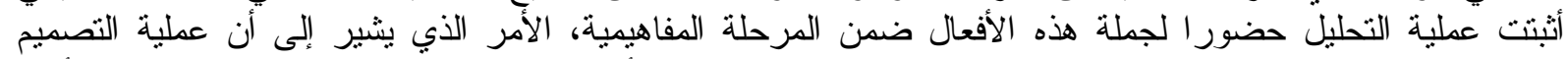

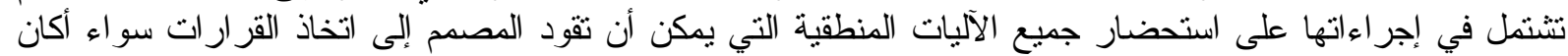

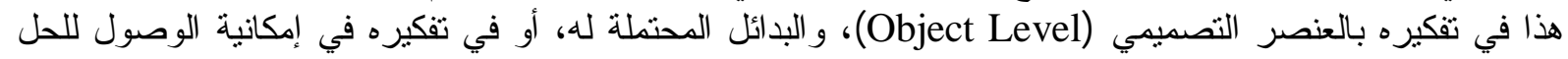

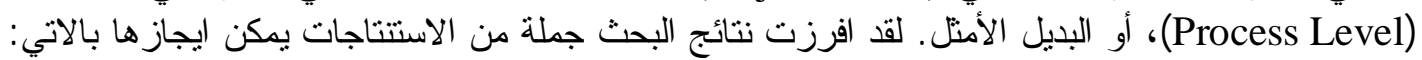

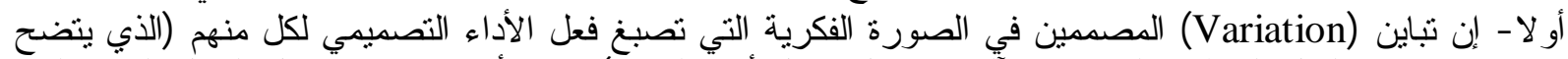

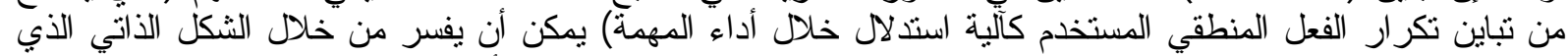

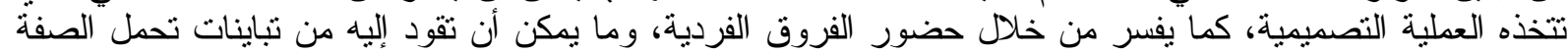

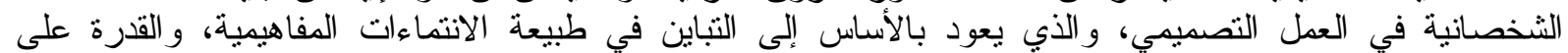

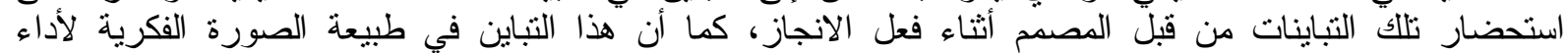

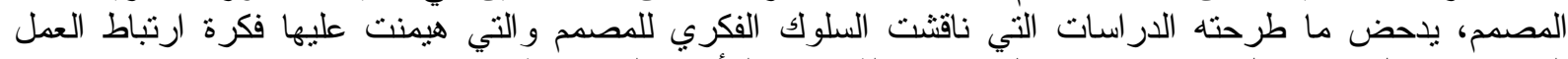

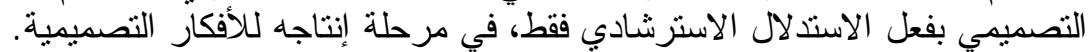

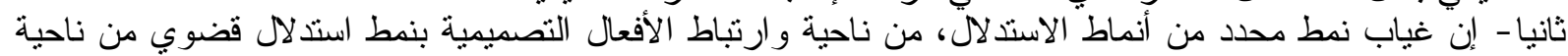

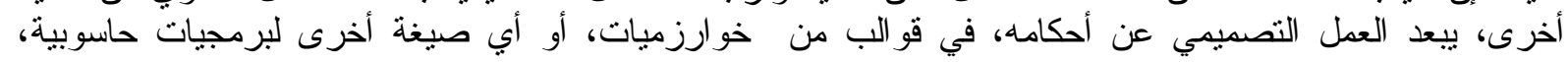


تفضي إلى تبني حزم برمجية عاملة، أو ذات كفاءة تصميمية مقبولة، وكل ما يمكن أن يحدث من محاو لات، سوف

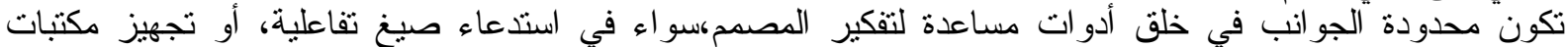
تصميمية لتسهيل دهمته، إلا إذا حدث، وتم تطوير برمجيات قادرة على إنشاء سلاسل منطقية قضوية، ولهاء القدرة على تلى

التفكير بشكل استرشادي.

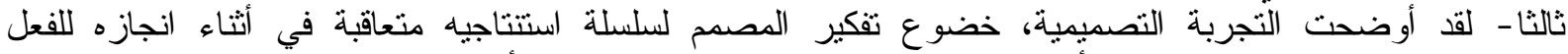

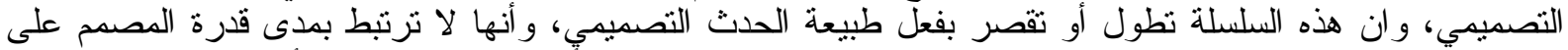

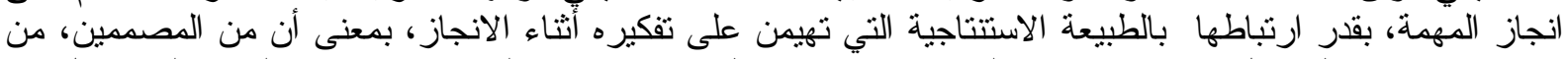

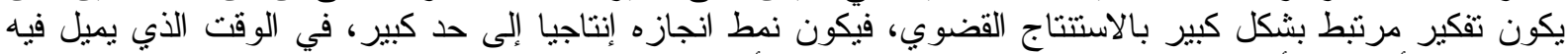

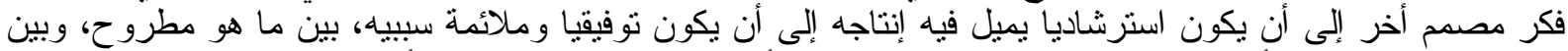

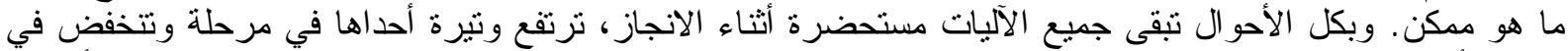

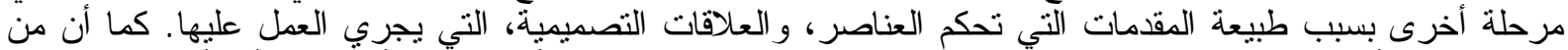

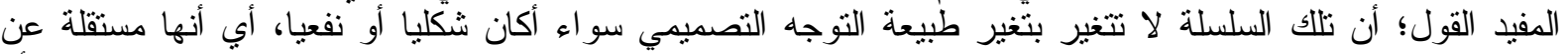
طبيعة نقطة البدء في التصميم، وفيما إذا كان المصدم يميل في تفكيره إلى معالجة التكوين المرئي للعمل التصميمي، أو التهائ

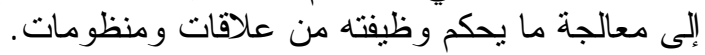

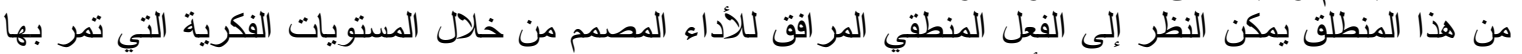

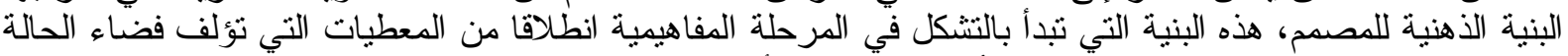

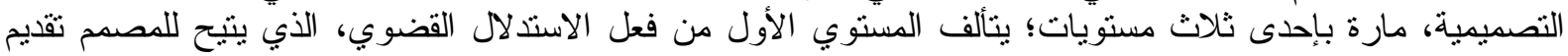

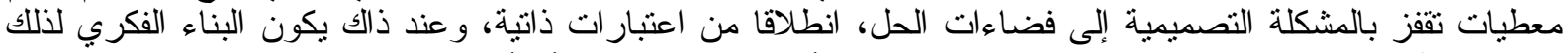

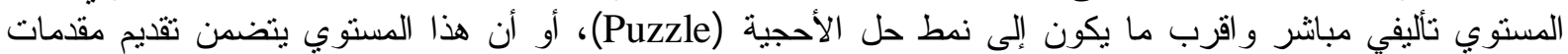

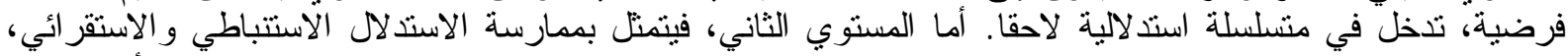

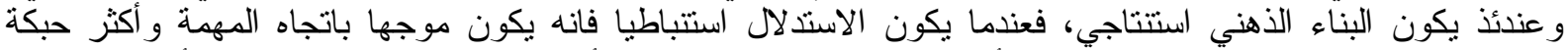

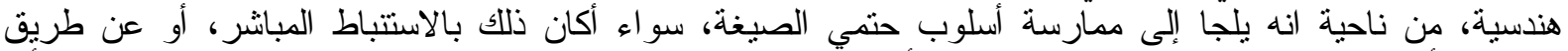

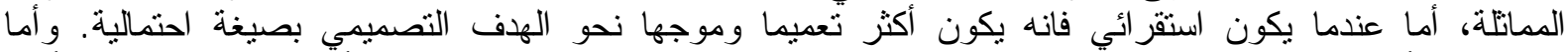

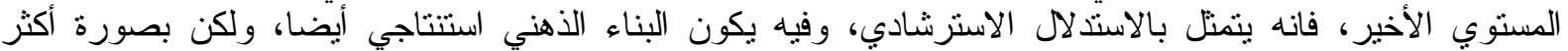

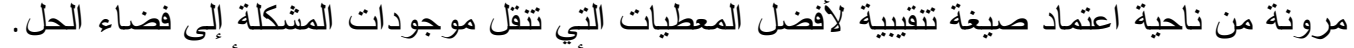

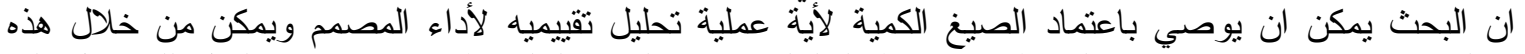

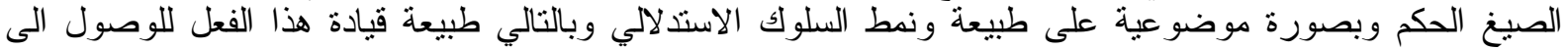
الاحكام المتعلقة بعملية التصميم التي يؤديها هذا السلوك.

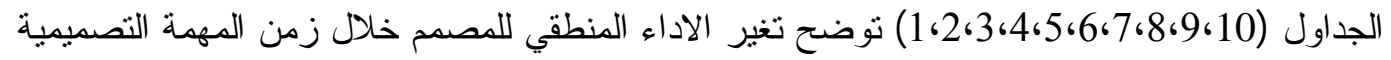

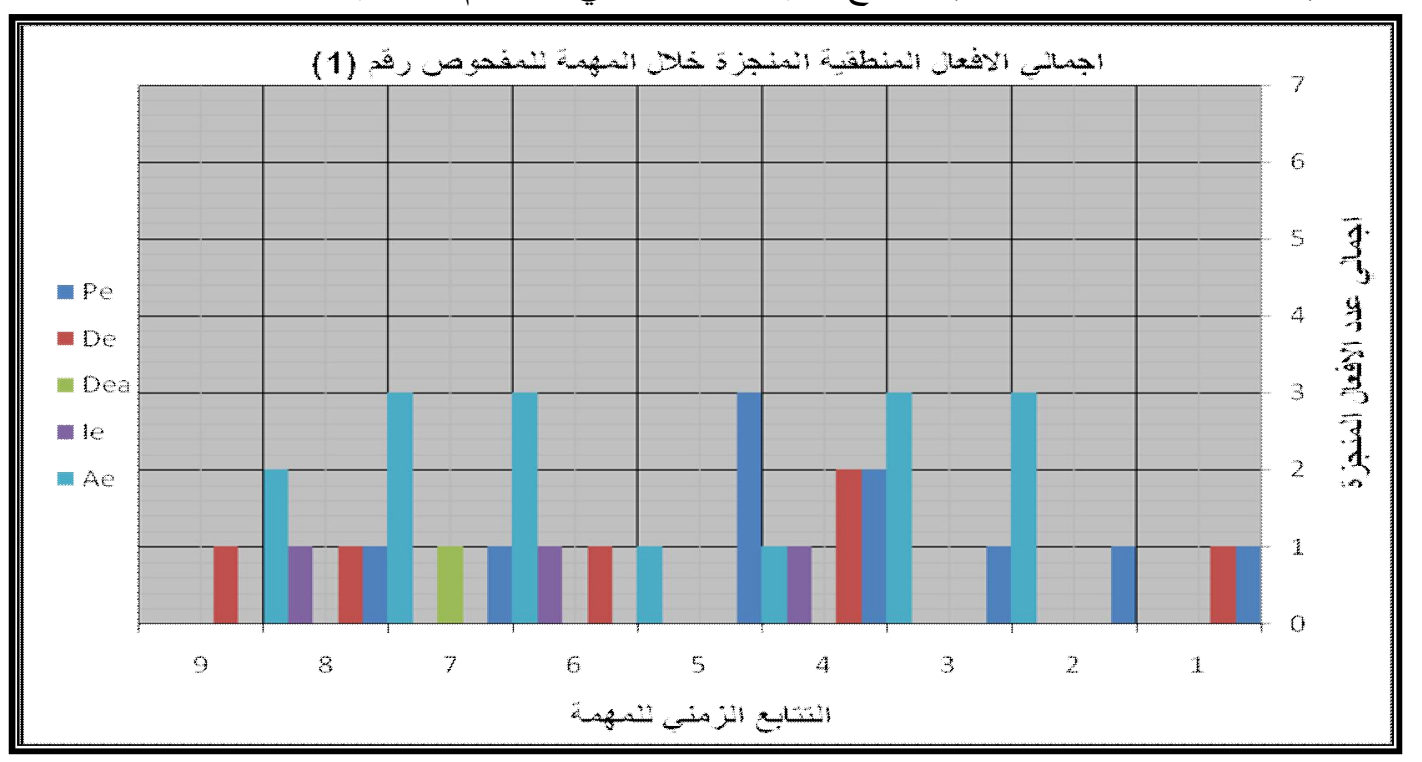


\begin{tabular}{llll} 
Al-Rafidain Engineering & Vol.17 & No.4 & August 2009 \\
\hline
\end{tabular}
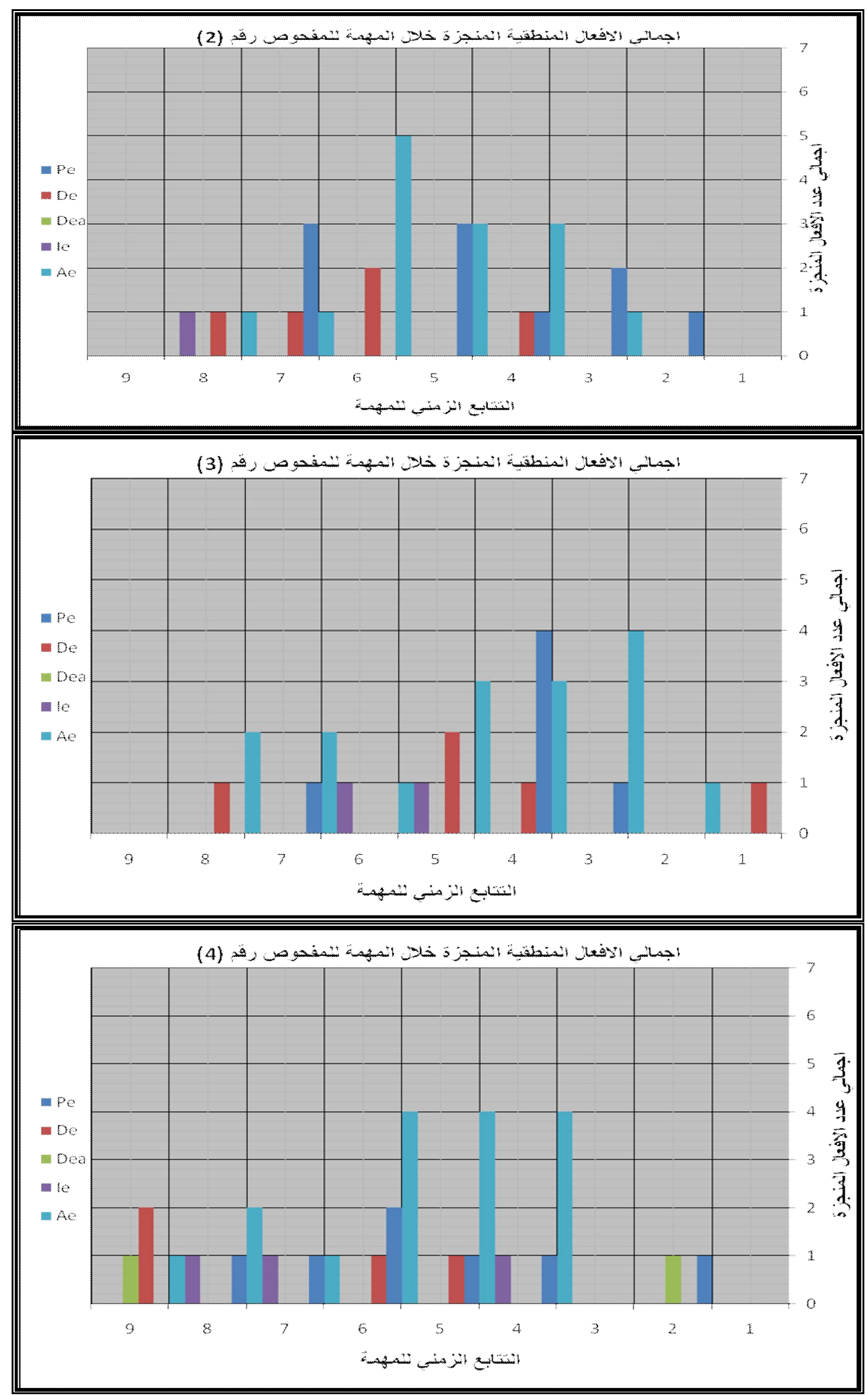

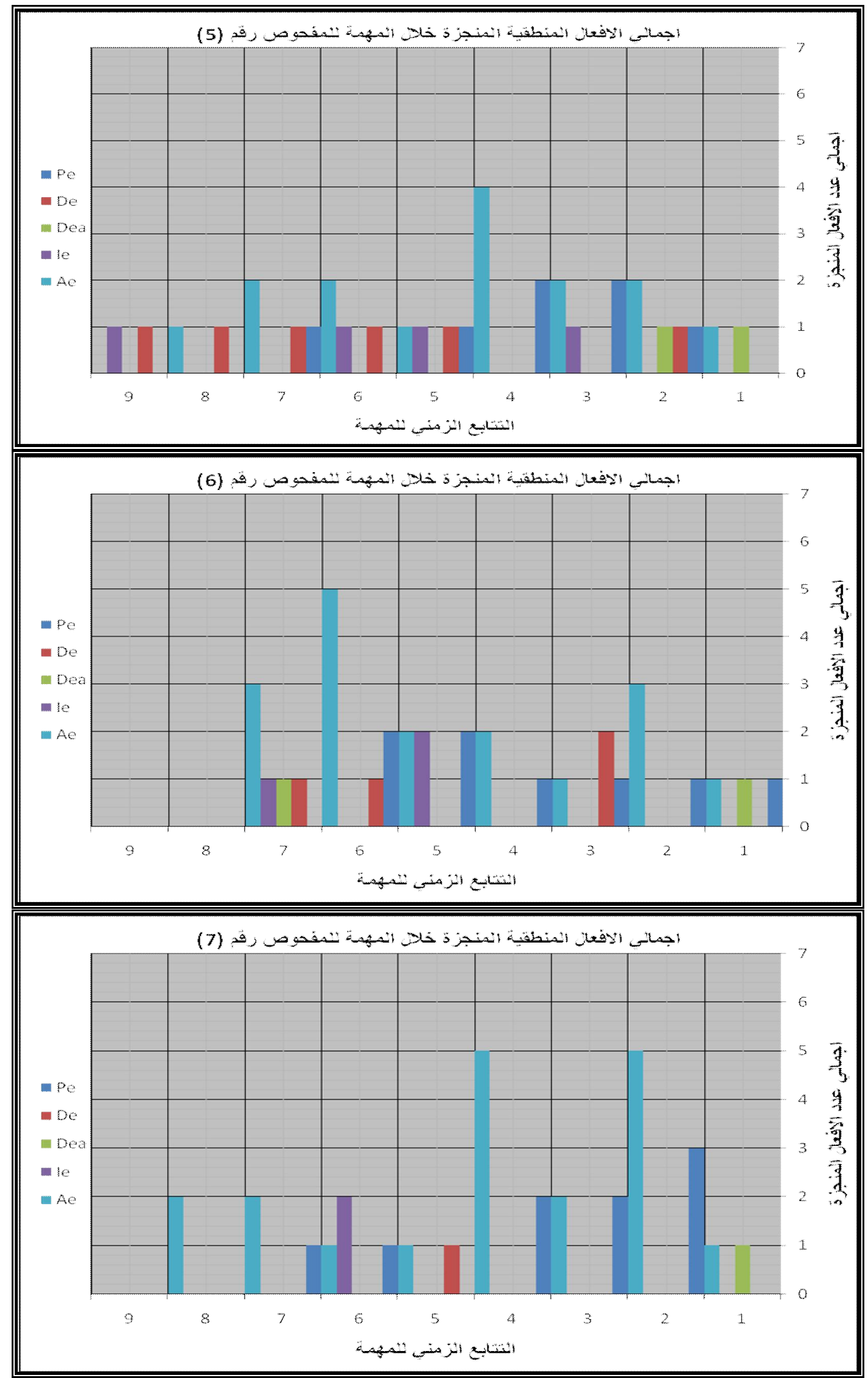
\begin{tabular}{lllll} 
Al-Rafidain Engineering & Vol.17 & No.4 & August 2009 \\
\hline
\end{tabular}
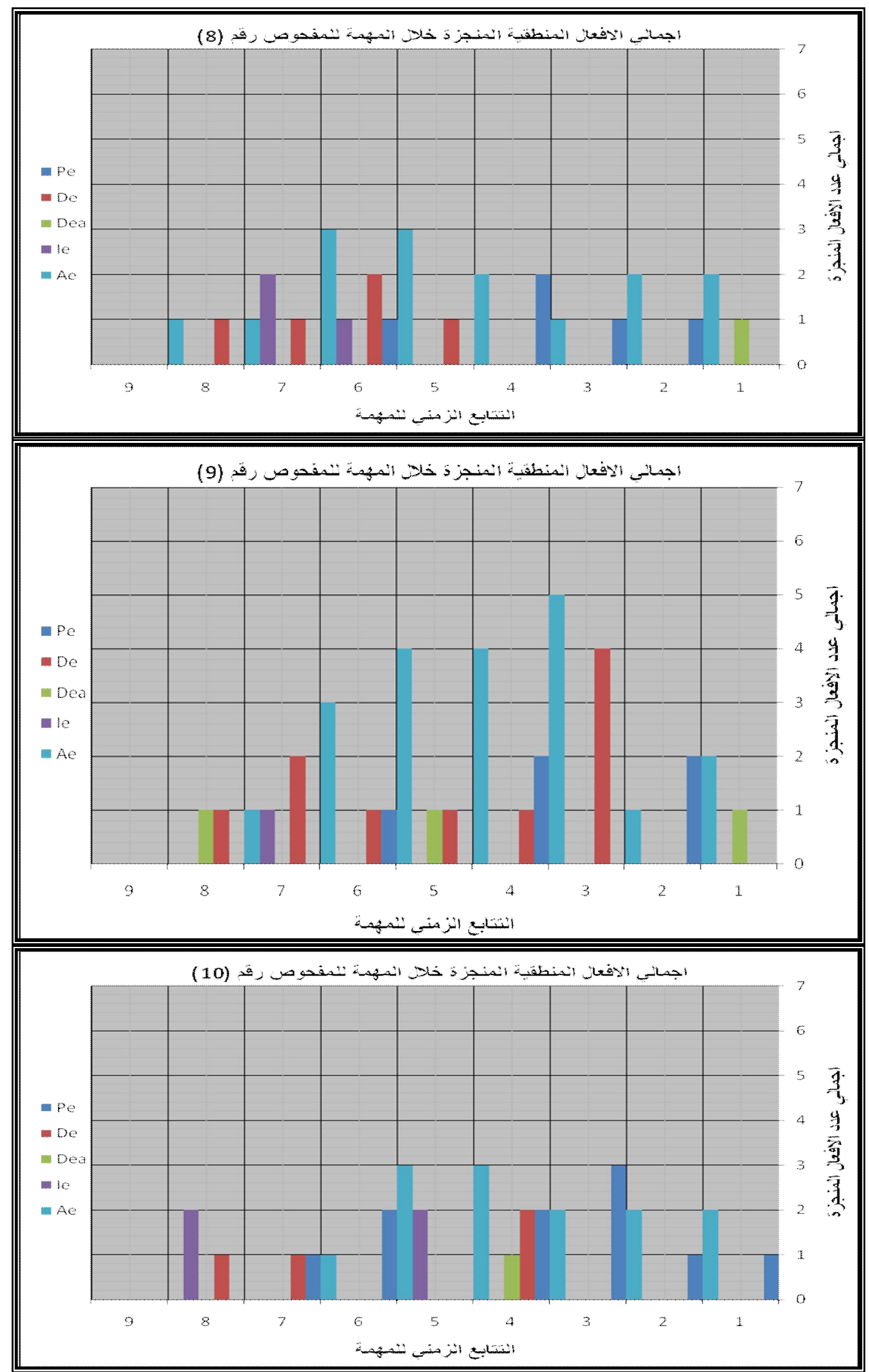

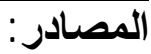


1- Bilda, Z., Gero, J., Analysis of a Blindfolded Architect's design Session, In, Gero, J., Tversky, B., \& Knight T., (Eds), VISUAL AND SPATIAL REASONING IN DESIGN III, Key Centre of Design Computing and Cognition, University of Sydney, Sydney, 2004

2- Gregory, S. A. THE DESIGN METHOD, Butterworth \& Co. Ltd, London, 1976.

3- Gross, N., (Ed), DEVELOPMENT IN DESIGN METHODOLOGY, John Wiley \& Sons, New York, 1984.

4- Jones J., C., DESIGN METHODS SEEDS OF HUMAN NEEDS, (2 ${ }^{\text {nd }}$ Ed.), John Wiley \& Sons Ltd. Chichester, 1992.

5- Kavakli, M., \& J., Gero, Sketching as mental imagery processing, Design Studies, Vol., 22, No., 4, 2001.

6- Lang, J., CREATING ARCHITECTURAL THEORY, The Role of the Behavioral Sciences in Environmental Design, Van Nostrand Reinhold company, New York, 1987.

7- Lawson, B. HOW DEESIGNERS THINK, the design process demystified ( $3^{\text {rd }}$ Ed) Architectural Press, Boston, 1997.

8- Lawson, B. WHAT DESIGNERS KNOW, ( $3^{\text {rd }}$ Ed) Architectural Press, Boston, 2004.

9- Leclercq, P., \& M., Locus, REPRESENTATION OF ARCHITECTURAL DESIGN PROCESS, International Design Conference, Dubrovnik, 14-17, May, 2002

10-March, L., (Ed), THE ARCHITECTURE OF FORM, Cambridge University Press, Cambridge, 1976.

11-McNeil, T., Gero, J., \& J., Warren, Understanding Conceptual Design Using Protocol Analysis, Research in Engineering Design, No. 10, 1999.

12-Mitchell, W., J., THE LOGIC OF ARCHITECTURE, DESIGN; COMPUTATION AND COGNITION, MIT Press, Cambridge, 1990.

13-Morris, C., \& A., Maisto, PSYCHOLOGY, $\left(10^{\text {th }}\right.$ Ed.), Prentice Hall Inc., New Jersey, 2004.

14-Suwa, M., Tversky, B., What Architects See in Their Sketches: Implications for Design Tools Advanced Research Laboratory, Hitachi Ltd., 2520, Hatoyama, Saitama, 350-03, Japan, 1996, No 81-492-96-6111.

15-Zeisel, J., INQUIRY BY DESIGN: TOOLS FOR ENVIRONMENT- BEHAVIOR RESEARCH, Cambridge University Press, Cambridge, 1984.

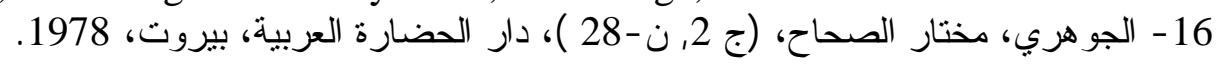

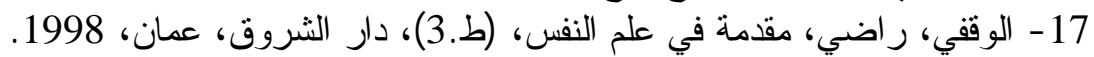

18 - القيماقجي ، ناهض، راف، البنية المنطقية لعملية التصميم المعماري، أطروحة دكتور اه،الجامعة التكنولوجية،بغداد 


\begin{tabular}{llll} 
Al-Rafidain Engineering & Vol.17 & No.4 & August 2009 \\
\hline
\end{tabular}

(ملحق رقم 1 التجربة المقدمة للمبحوثين وبرنامجها الوظيفي)

بسم الله الرحمن الرحيم

نموذج مهمة تصميمية

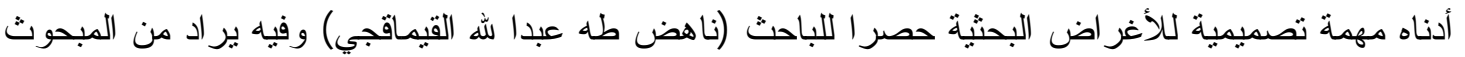

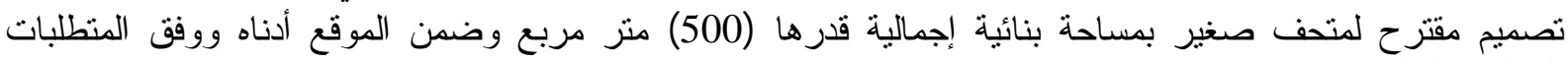

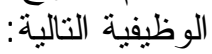

1 - منطقة مدخل واستقبال تتضمن استعلامات

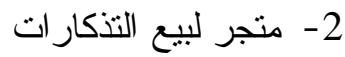

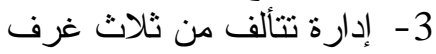

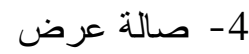

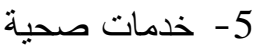

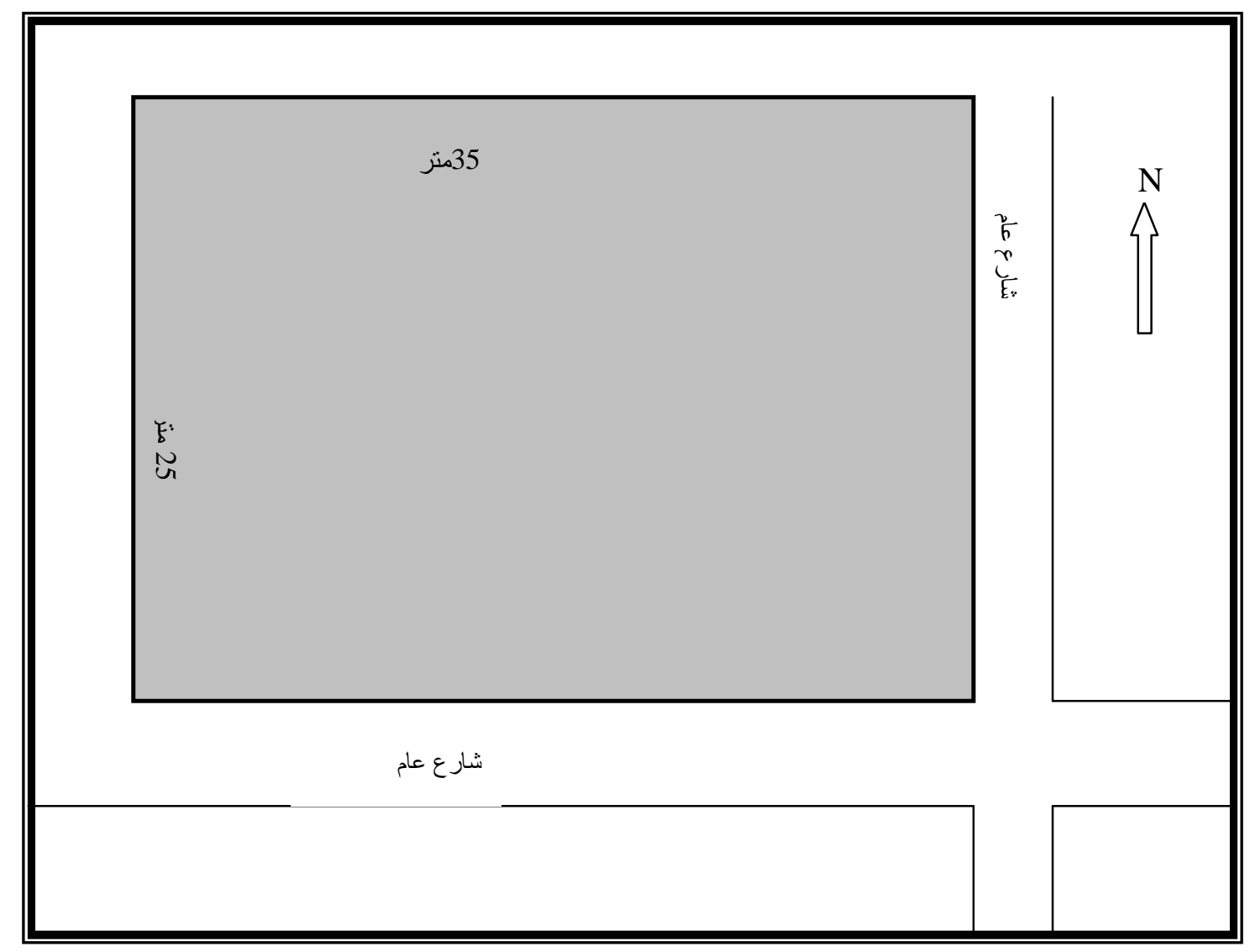

ملاحظات عامة

1 - اللمبحوث استخدام عدد غير محدد من الأوراق لرسم المقترح التصميمي.

2 - الزمن الإجمالي لانجاز المهمة لا يتعدى (45) دقال الإيقة.

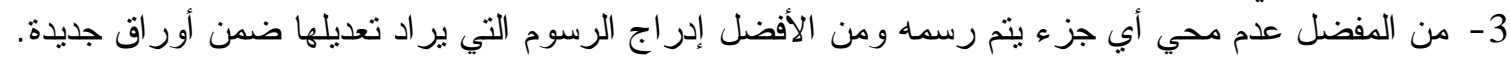

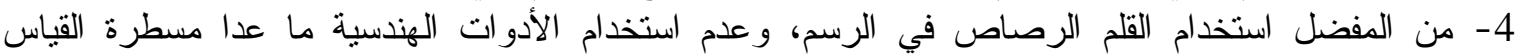
.(scale ruler)

(ملحق رقم 2 يوضح نمط تحليل الفعالية المنطقية لإحدى المهام التصميمية) 


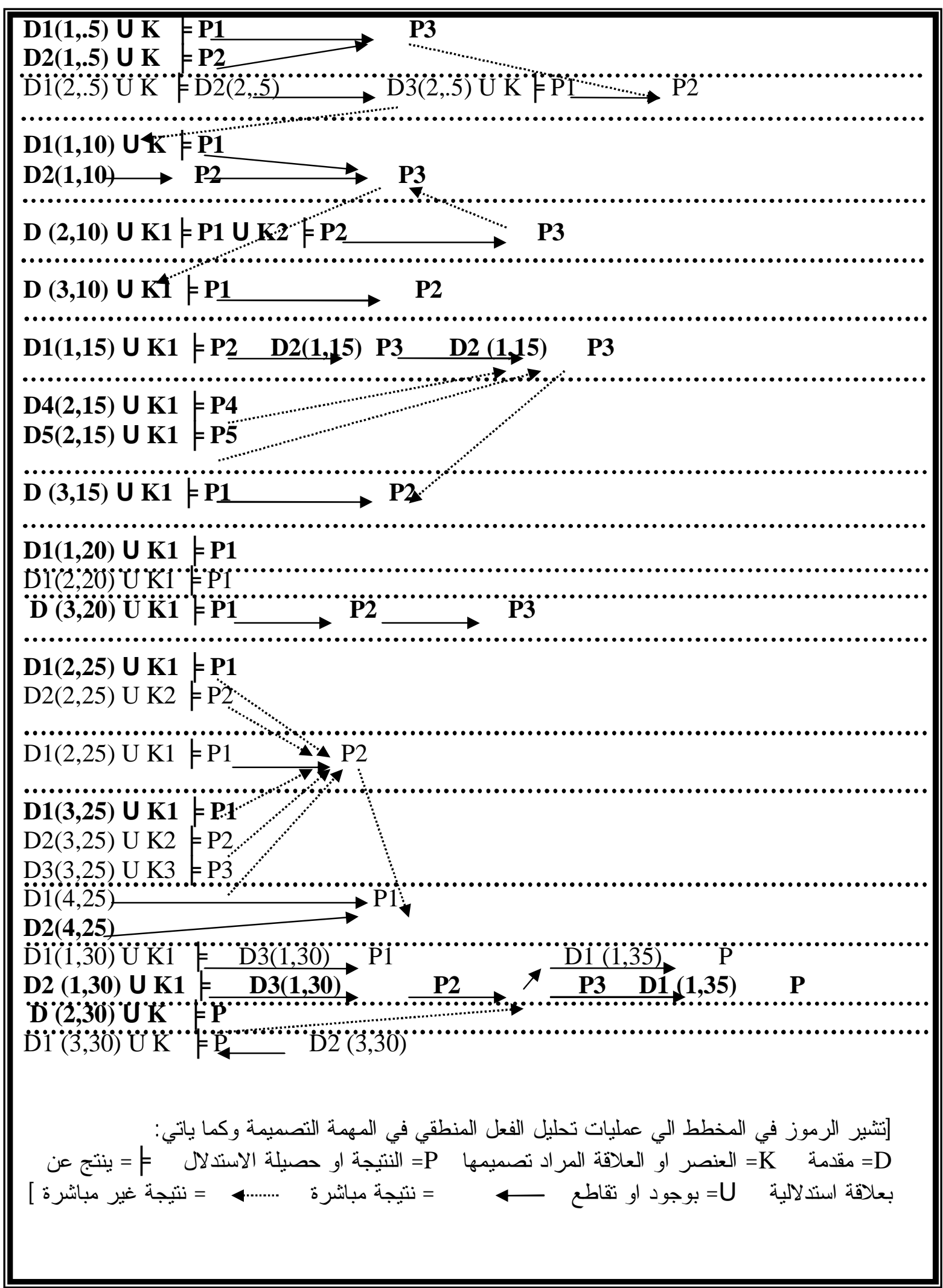

\section{تم اجراء البحث في كلية الهندسة ـ جامعة الموصل}

